\title{
Arctic climate change in 21 st century CMIP5 simulations with EC-Earth
}

\author{
Torben Koenigk • Laurent Brodeau • Rune Grand Graversen • \\ Johannes Karlsson • Gunilla Svensson • Michael Tjernström • \\ Ulrika Willén · Klaus Wyser
}

Received: 1 March 2012/Accepted: 20 August 2012/Published online: 1 September 2012

(C) The Author(s) 2012. This article is published with open access at Springerlink.com

\begin{abstract}
The Arctic climate change is analyzed in an ensemble of future projection simulations performed with the global coupled climate model EC-Earth2.3. EC-Earth simulates the twentieth century Arctic climate relatively well but the Arctic is about $2 \mathrm{~K}$ too cold and the sea ice thickness and extent are overestimated. In the twenty-first century, the results show a continuation and strengthening of the Arctic trends observed over the recent decades, which leads to a dramatically changed Arctic climate, especially in the high emission scenario RCP8.5. The annually averaged Arctic mean near-surface temperature increases by $12 \mathrm{~K}$ in RCP8.5, with largest warming in the Barents Sea region. The warming is most pronounced in winter and autumn and in the lower atmosphere. The Arctic winter temperature inversion is reduced in all scenarios and disappears in RCP8.5. The Arctic becomes ice free in September in all RCP8.5 simulations after a rapid reduction event without recovery around year 2060. Taking into account the overestimation of ice in the twentieth century, our model results indicate a likely ice-free Arctic in September around 2040. Sea ice reductions are most pronounced in the Barents Sea in all RCPs, which lead to the most dramatic changes in this region. Here, surface heat fluxes are strongly enhanced and the cloudiness is substantially decreased. The meridional heat flux into the
\end{abstract}

T. Koenigk $(\bowtie) \cdot$ U. Willén · K. Wyser

Rossby Centre, Swedish Meteorological

and Hydrological Institute, 60176 Norrköping, Sweden

e-mail: torben.koenigk@smhi.se

L. Brodeau · R. G. Graversen · J. Karlsson - G. Svensson •

M. Tjernström

Department of Meteorology and Bert Bolin Centre

for Climate Research, Stockholm University,

10654 Stockholm, Sweden
Arctic is reduced in the atmosphere but increases in the ocean. This oceanic increase is dominated by an enhanced heat flux into the Barents Sea, which strongly contributes to the large sea ice reduction and surface-air warming in this region. Increased precipitation and river runoff lead to more freshwater input into the Arctic Ocean. However, most of the additional freshwater is stored in the Arctic Ocean while the total Arctic freshwater export only slightly increases.

Keywords Arctic climate - Future scenarios - CMIP5 Global coupled atmosphere-ocean modeling .

Coupled Arctic climate processes

\section{Introduction}

The Arctic region plays an important role in the global climate system. Snow and ice cover have a large influence on both the local and remote climate (Magnusdottir et al. 2004; Alexander et al. 2004; Koenigk et al. 2009; Deser et al. 2010; Overland and Wang 2010). The export of freshwater from the Arctic alters the deep water formation in the North Atlantic (Häkkinen 1999; Haak et al. 2003; Koenigk et al. 2006). Dickson et al. (1988) and Belkin et al. (1998) suggested that the so called "Great Salinity Anomaly" in the early 70s was caused by previous large Fram Strait sea ice exports. Jungclaus et al. (2005) and Holland et al. (2001) stressed the importance of variations in the Arctic freshwater export for the variability of the meridional overturning circulation (MOC).

Observations of the last decades show an ongoing climate change in the Arctic regions. The observed warming in the Arctic is about twice or more the rate of the global mean warming in the last decades (ACIA 2005; IPCC 2007; Richter-Menge and Jeffries 2011). Most likely, the 
ice-albedo feedback (Serreze et al. 2009; Screen and Simmonds 2010b), enhanced meridional energy transport (Graversen et al. 2008), changes in clouds and water vapour (Graversen and Wang 2009; Liu et al. 2008) and the weak vertical mixing in Arctic winter inversion (Bintanja et al. 2011) are contributing to this Arctic warming amplification.

The observed warming is concurrent with a large reduction of sea ice cover in the last decades (Comiso et al. 2008) with recent extreme September minimums in 2007 and 2011. Possible explanations for the rapid ice reduction in 2007 are pre-conditioning by ice thinning in the previous years along with anomalous winds in summer and the ice-albedo feedback during the 2007 summer (Zhang et al. 2008), advection of warm and humid air in the beginning of the melting season (Graversen et al. 2011), cloud and radiation anomalies (Kay et al. 2008) and increased ocean heat inflow through Bering Strait (Steele et al. 2010).

Model simulations of the future climate indicate an accelerated climate change in the Arctic in the twenty-first century. The simulated warming in the Arctic in the climate projections discussed in the International Panel of Climate Change (IPCC) Fourth Assessment Report (AR4) is by far larger than the global mean warming (Chapman and Walsh 2007). However, the spread between different models is large (e.g. Holland and Bitz 2003, Sorteberg et al. 2005).

Most AR4 models overestimate today's sea ice extent and underestimate the ice reduction trend compared to observations. Only a few models show an ice-free Arctic in September by the end of the twenty-first century (Stroeve et al. 2007). However, global coupled simulations by Holland et al. (2006) and regional Arctic simulations by Koenigk et al. (2011) showed near ice-free summer conditions around 2050 and 2040, respectively. Wang and Overland (2009) used ice conditions of 2007/2008 as starting point in 6 selected AR4-models and found a substantial likelihood for an ice-free September around 2030.

In this study, we give an overview of Arctic climate change based on an ensemble of twenty-first century IPCC AR5-future climate projections with the global coupled climate model EC-Earth.

The article is organized as follows: the next section provides a description of the model and the scenario simulations. Section 3 describes the performance of the model in the twentieth century and changes in atmosphere, ocean and sea ice in the twenty-first century and compares the responses for the different emission scenarios (RCPs, Representative Concentration Pathways). In the final section, the results are summarized and discussed.

\section{Model, simulations and data}

\subsection{Model description}

The model used in this study is the global coupled climate model EC-Earth (Hazeleger et al. 2010). The Integrated Forecast System (IFS) of the European Centre for Medium Range Weather Forecasts (ECMWF) constitutes the atmosphere component, and the Nucleus for European Modelling of the Ocean (NEMO), developed by the Institute Pierre Simon Laplace (IPSL), the ocean component (Madec 2008). Here, we used the model version 2.3.

The atmosphere component is used at a T159 resolution with 62 vertical levels. It is based on cycle $31 \mathrm{r} 1$ of IFS, but also includes some improvements from later cycles. The most important improvements are the convection scheme by Bechtold et al. (2008), the land surface scheme H-TESSEL (Balsamo et al. 2009), and a new snow scheme (Dutra et al. 2010).

The ocean component uses a tri-polar grid with poles over northern North America, Siberia and Antarctica and a resolution of about $1^{\circ}$ and 42 vertical levels. It is based on NEMO version 2.0 and includes the Louvain la Neuve seaice model version 2 (LIM2, Fichefet and Morales Maqueda 1997; Bouillon et al. 2009), which is a dynamic-thermodynamic sea-ice model. The atmosphere and ocean/sea ice parts are coupled through the OASIS (Ocean, Atmosphere, Sea Ice, Soil) coupler (Valcke 2006). Bathymetry and topography of the ocean and atmosphere model, respectively, are shown in Fig. 1.

The climate of the model in present-day and preindustrial control simulations is described in more details by Sterl et al. (2012) and Hazeleger et al. (2012).

\subsection{Scenario simulations}

An ensemble of historical simulations (1850-2005) and future simulations (2006-2100) based on forcing schemes suggested by the Coupled Model Intercomparison Project phase 5 (CMIP5) was performed with EC-Earth. An ensemble of three historical twentieth century simulations was obtained by initializing from different times of a long pre-industrial simulation with EC-Earth. From each of the twentieth century simulation, two scenario simulations were carried out, based on the Representative Concentration Pathways (RCP) 4.5 and 8.5 emission scenarios. One RCP2.6 simulation was also performed starting from one of the three historical simulations. These three RCPs, along with a fourth (RCP6.0), were selected by the IPCC as representative for the literature. The RCPs are named according to the radiative forcing target level at year 2100 . RCP2.6 is a mitigation scenario, leading to a low forcing level at the end of the tweny-first century $\left(2.6 \mathrm{~W} / \mathrm{m}^{2}\right)$, 
(a) ocean model

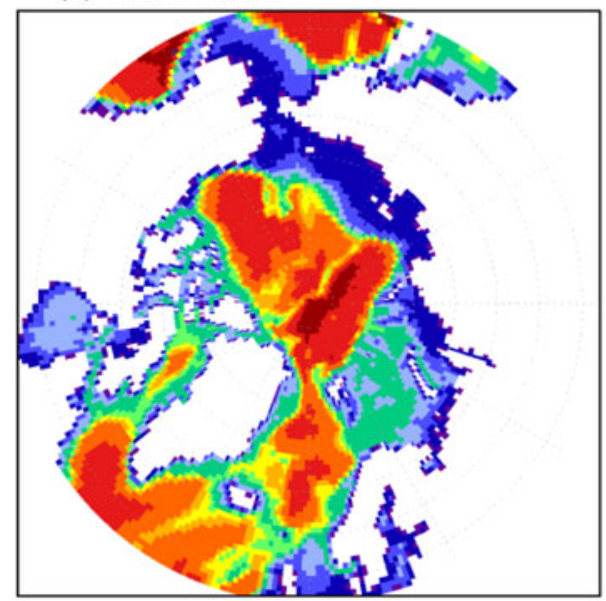

(b) atmosphere model

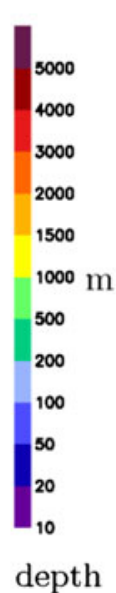

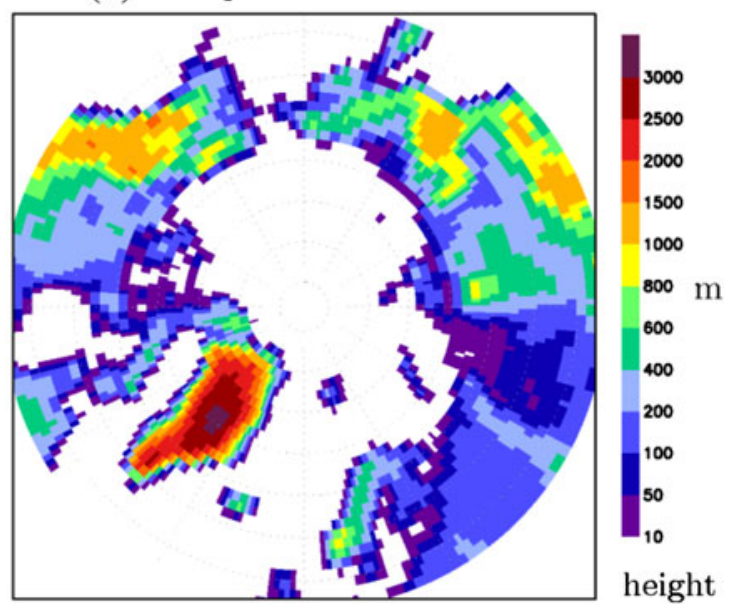

Fig. 1 Bathymetry of the ocean model (a) and topography of the atmosphere model (b)

RCP4.5 and RCP6 are two medium stabilization scenarios, while RCP8.5 is a high emission scenario (Moss et al. 2010; van Vuuren et al. 2011).

In the following sections, ensemble means are used if nothing else is stated. Note that only one RCP2.6 scenario simulation was performed.

\subsection{Observations and data}

The twentieth century simulations with EC-Earth are compared to available observational data, satellite products, results from the literature and the ERA-interim reanalysis.

In many cases, direct observations are not available or coarse in space and time in the Arctic. Particularly for the ocean, no comprehensive data sets are existing. Instead EC-Earth results are compared to a number of different results from the literature.

We use satellite products to evaluate sea ice concentration and clouds in EC-Earth. The satellite sea ice concentration data are generated from brightness temperature data derived from the following sensors: the Nimbus-7 Scanning Multichannel Microwave Radiometer (SMMR), the Defense Meteorological Satellite Program (DMSP) -F8, -F11 and -F13 Special Sensor Microwave/Imagers (SSM/Is), and the DMSP-F17 Special Sensor Microwave Imager/Sounder (SSMIS) (Cavalieri et al. 1996, updated yearly). The data are provided in the polar stereographic projection at a grid cell size of $25 \times 25 \mathrm{~km}$. The data are generated using the National Aeronautics and Space Administration (NASA) Team algorithm developed by the Oceans and Ice Branch, Laboratory for Hydrospheric Processes at NASA Goddard Space Flight Center (GSFC).

The clouds are compared to satellite estimates from the Advanced Very High Resolution Radiometer (AVHRR)
Polar Pathfinder (APP-x, Wang and Key 2005; Karlsson and Svensson 2011). The APP-x product includes retrievals of all-sky surface skin temperature, cloudiness, radiative fluxes and surface cloud forcing, derived by algorithms of the Cloud and Surface Parameter Retrieval (CASPR) system (Key 2002). The APP-x retrievals have been optimized for high latitude conditions.

In addition to direct observations and satellite data we compare our model results throughout this study to the ERA-Interim reanalysis. This is the latest in a series of reanalysis products from the European Centre for Medium Range Weather Forecasting (ECMWF, Dee et al. 2011). In essence a reanalysis constitutes an optimal blend of model data and observations; observations are assimilated to prevent the model from drifting away from the real state of the atmosphere, while the model provides a global data set that includes a temporal and three-dimensionally spatial development of a multitude of variables for more than four decades. Of special interest for such comparisons is the fact that ERA-Interim and EC-Earth in principle employ the same atmospheric model.

ERA-Interim is based on a version of the ECMWF forecast model (Cy31r2), essentially the same as EC-Earth but run at a spectral resolution of T255 with 60 hybridcoordinate levels. It represents a newer generation of reanalysis relative to the earlier products, e.g. NCAR/ NCEP from the National Center for Atmospheric Research (Kalnay et al. 1996) and ERA-40 from the ECMWF (Uppala et al. 2005), and many aspects of both the model and assimilation systems have been improved (see Dee et al. 2011 for a detailed account of model changes between ERA-40 and ERA-Interim).

When results from EC-Earth are compared to data from ERA-Interim one has to keep in mind that the Arctic is a data sparse region and also that for some variables ERA-Interim is 
just as much a model as EC-Earth. To the extent that observations are not available in the Arctic, the data assimilation obviously provides less value, although effects from more southerly locations with better observational coverage should have a positive impact. But some variables, for example turbulent heat fluxes and cloud properties, are neither observed nor assimilated and are thus governed by the model physics and the state variables, assimilated from observations which may be few in the Arctic. The surface fields also play an important role. For the ocean these are simulated independently in EC-Earth but are prescribed from observations in ERA-Interim, while for the land surface they are simulated in both, although some near-surface atmospheric observations are assimilated in ERA-Interim.

\section{Results}

Future changes in atmosphere, ocean and sea ice are closely linked, and it is often difficult to distinguish between causes and effects. In this section, we will-along with some evaluation of the simulated twentieth century Arctic climate-focus on the mean changes of Arctic key variables in the different EC-Earth future projections. Although we will briefly discuss the relation between key variables and indicate important processes that are involved in Arctic climate change we will leave detailed process analyses for future studies.

\subsection{Arctic sea ice}

Observations of the northern hemispheric ice extent during the last 30 years show a strong and accelerated negative trend, particularly during late summer. EC-Earth underestimates this trend in September but not in March and overestimates the ice extent both in September and March at the end of the twentieth century and beginning of the twenty-first century (Fig. 2). It is not until 2030-2040 that ice extents and trends in EC-Earth are comparable to today's observations. Also, the modelled Arctic sea ice volume (not shown) is overestimated in the twentieth century compared to estimates of today's observed ice volume (e.g. Belchansky et al. 2008; Rothrock et al. 2003). As for the ice extent, the simulated ice volume around 2030-2040 is comparable to today's estimates. Thus, the relation between ice volume and extent in EC-Earth seems to be realistic.

The reduction of sea ice extent until 2050 is similar in all three projections. Thereafter, the decrease of sea ice extent differs strongly between the three different RCPs. The simulated September sea ice extent in RCP2.6 stabilizes after an abrupt increase around 2070 at about 1.5 million $\mathrm{km}^{2}$ below the modelled extent at the beginning of the twenty-first century. In RCP4.5, the reduction continues until around year 2070 and seems to stabilize on a very low level thereafter. The differences between the three RCP4.5 ensemble members is more pronounced after 2070 and several reduction events occur with partial recoveries thereafter. In RCP8.5, an abrupt sea ice reduction, which leads to almost total sea ice loss in September, takes place in all three members around 2060 without any recovery thereafter. The rapid sea ice reductions in RCP8.5 happen at a $\mathrm{CO}_{2}$ concentration of about $600 \mathrm{ppm}$. This is an increase of $115 \mathrm{ppm}$ compared to year 2040, where EC-Earth simulates ice conditions similar to the observed conditions around 2010. Adding this $115 \mathrm{ppm}$ to today's $\mathrm{CO}_{2}$ concentration, the real world threshold, if existing, for an ice-free September would be around $500 \mathrm{ppm}$. This level is reached around 2040 and 2055 in RCP4.5 and RCP8.5, respectively. In RCP2.6, $\mathrm{CO}_{2}$ concentrations stay below $500 \mathrm{ppm}$ through the entire twenty-first century indicating a low likelihood for an ice-free September.

The sea ice change in EC-Earth is strong compared to most CMIP3 models (Stroeve et al. 2007; Wang and Overland 2009); only a few CMIP3 models simulate an Arctic sea ice loss before 2060. However, due to different emission scenarios, the results are not completely comparable. RCP8.5 simulations with CCSM4 (Vavrus et al. 2011) show an ice free Arctic in September around 2070. This is slightly later than in our model even though CCSM4 starts with a lower initial ice extent in the end of the twentieth century.

Figures 3 and 4 show the spatial distribution of the annually averaged sea ice thickness and concentration at the end of the twentieth century, and changes by the end of the twenty-first century. Sea ice thickness reaches 3-4.5 m in most of the Central Arctic. Compared to existing observations and estimates of the ice thickness (Rothrock et al. 2003; Belchansky et al. 2008), this is an overestimation by about $0.5-1 \mathrm{~m}$. At the Siberian coast, the overestimation is even larger, which is a typical problem of many coupled climate models and at least partly due to too weak offshore winds at the Siberian coast (Bitz et al. 2002; DeWeaver and Bitz 2006). The thick ice at the Siberian coast prevents the complete melting of ice during summer in this area. Along most ice edges, particularly in the Greenland Sea, sea ice extends slightly further south than in observations (Fig. 4b).

Ice thickness reductions until 2080-2100 are relatively uniform in the Central Arctic and reach $1-1.5 \mathrm{~m}$ in RCP2.6, $2-3 \mathrm{~m}$ in RCP4.5 and up to $4 \mathrm{~m}$ in RCP8.5. The largest sea ice concentration changes take place in the Barents Sea (Fig. 4c-e). Ice concentration is also substantially reduced along the ice edges of the Labrador and Greenland Seas. Here, the overestimation of sea ice in the twentieth century might contribute to the large reduction 
Fig. 2 March (dashed) and September (solid) sea ice extent in $\mathrm{m}^{2}$ in the northern hemisphere in the twentieth century simulations (black), RCP4.5 (blue), RCP8.5 (red), RCP2.6 (green) with EC-Earth and in satellite observations (stars)

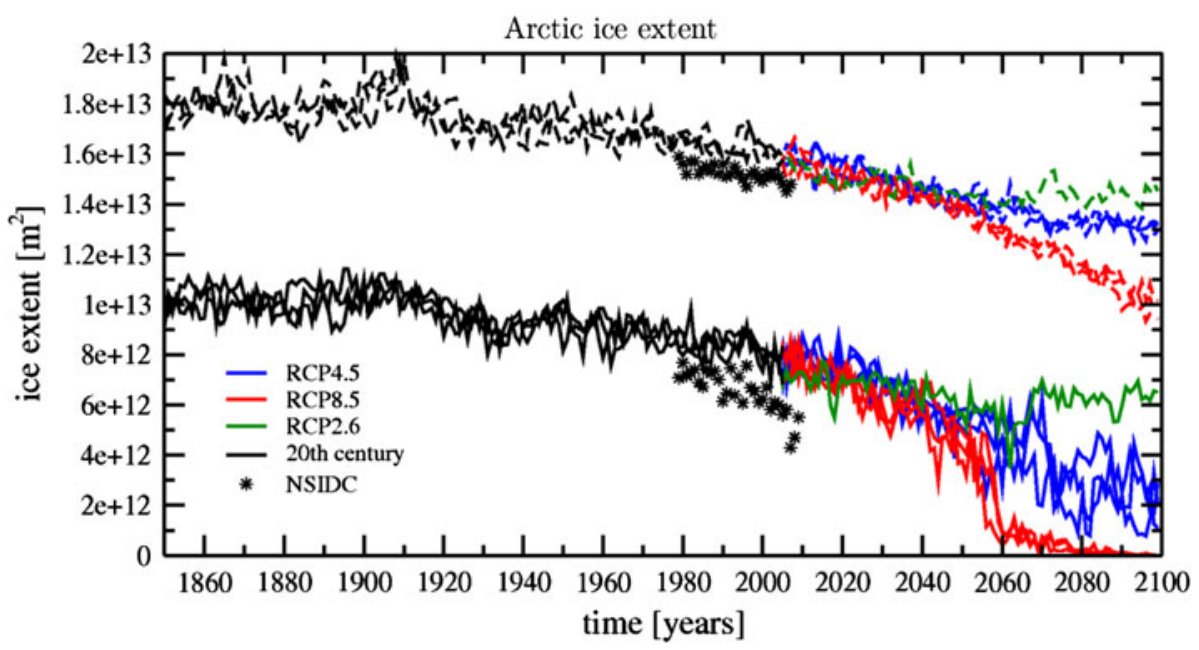

(a) sea ice thickness, 1980-1999

Fig. 3 a Annual mean sea ice thickness in $\mathrm{m}$ in EC-Earth, averaged over 1980-1999. b-d Change in annual mean sea ice thickness between 2080-2099 and 1980-1999 in RCP2.6 (b), RCP4.5 (c) and RCP8.5 (d). Shown are ensemble means. Note that there is only one RCP2.6 simulation

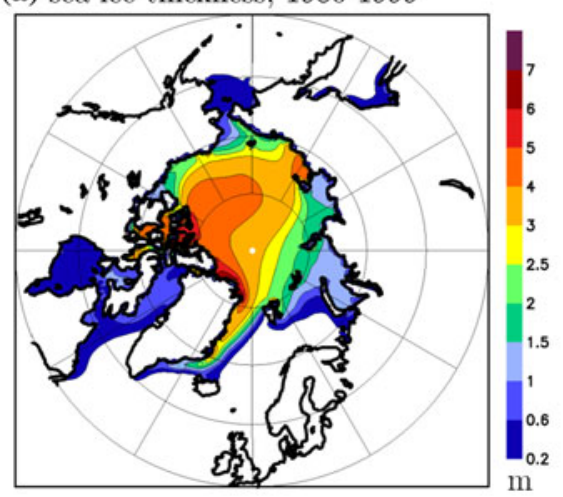

(c) RCP4.5, 2080-2099 - 1980-1999

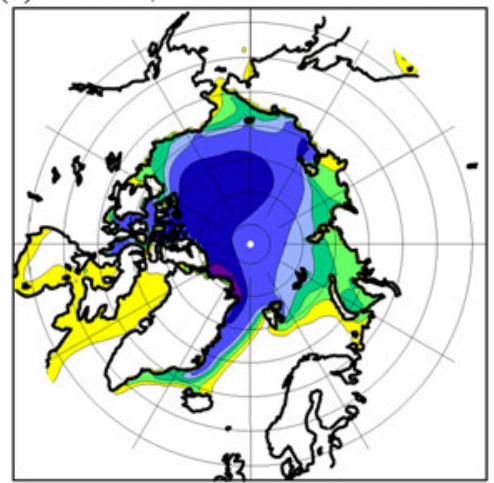

(b) RCP2 6, 2080-2099 - 1980-1999

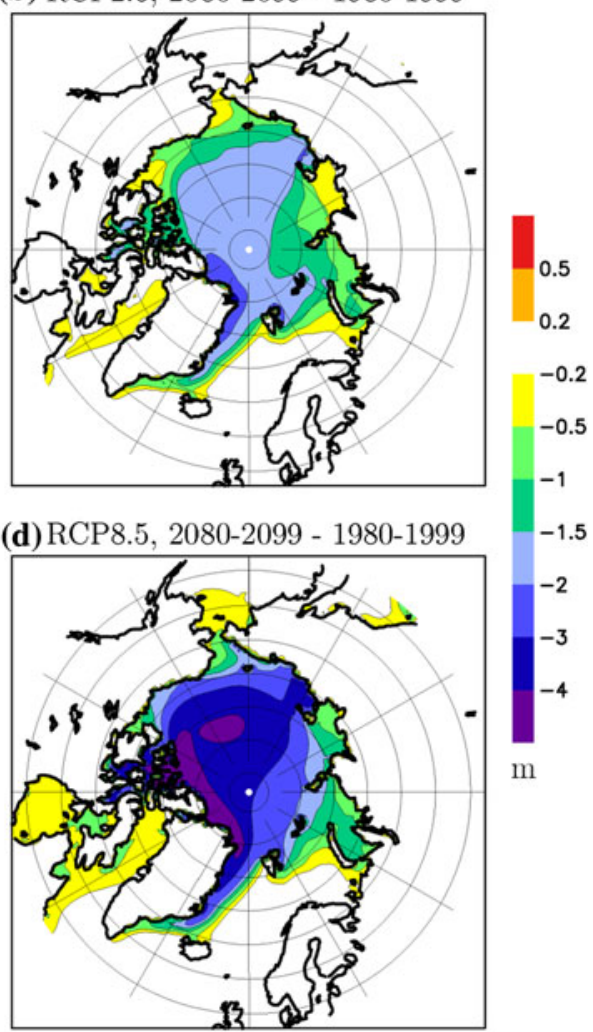

rates. Ice concentration changes are small in the Central Arctic, but still significant at the $95 \%$-level in all scenarios due to low interannual variability of ice concentration in the interior of the Arctic. The sea ice reduction in the Central Arctic is growing with increasing emissions and in RCP8.5, sea ice concentration is strongly reduced almost everywhere. The seasonal mean changes (Fig. $4 \mathrm{f}-\mathrm{i}$, only shown for RCP4.5) indicate the largest reduction in autumn, while in winter and spring the reduction is limited to the ice edges. The Barents Sea region has the largest ice concentration decrease in the Arctic throughout all seasons.
The annual cycle of sea ice concentration changes have a similar pattern in RCP8.5 and RCP2.6 but the amplitudes differ.

\subsection{Turbulent heat fluxes}

Figure 5 shows modeled annual-averaged surface sensible and latent heat fluxes for the present climate, differences to ERA-Interim and changes for the two higher emission scenarios, RCP4.5 and RCP8.5. Averaged over the polar ice cap the fluxes are close to zero (Fig. 5a, b). The 
(a) sea ice concentration, 1980-1999

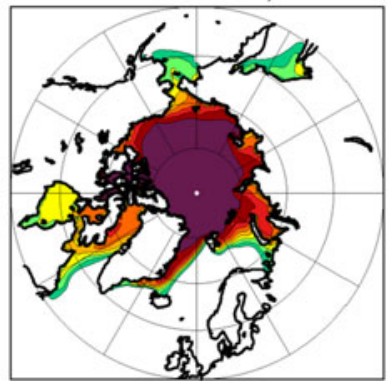

(b) EC-Earth - sat obs, 1980-1999

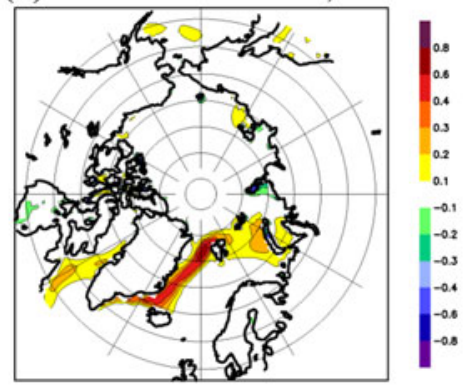

Change between 2080-2099 and 1980-1999

(c) RCP2.6

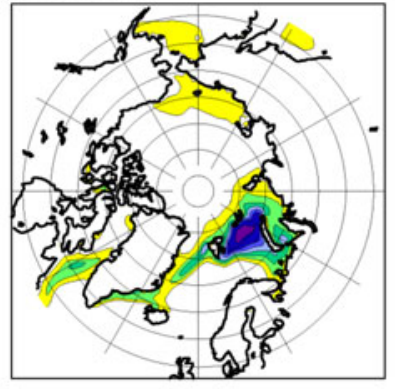

(d) $\mathrm{RCP} 4.5$

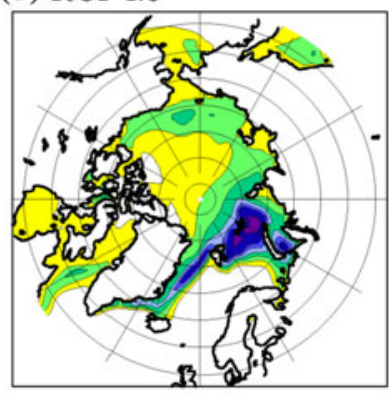

(g) RCP4.5, MAM
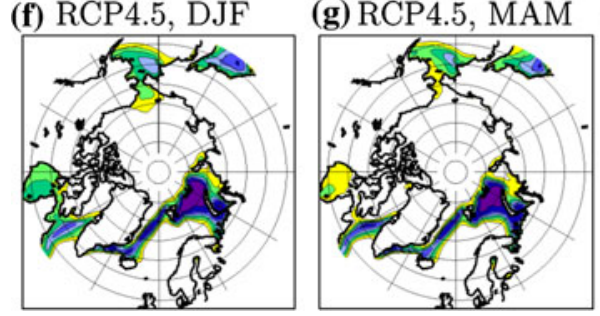

Fig. 4 a Annual mean sea ice concentration in EC-Earth, averaged over 1980-1999 and b difference to satellite observations (Cavalieri et al. 1996). c-e Change in annual mean sea ice concentration between 2080-2099 and 1980-1999 in RCP2.6 (c), RCP4.5 (d) and

open-ocean is dominated by the upward fluxes in the northern North Atlantic, which are up to $100 \pm 35 \mathrm{~W} / \mathrm{m}^{2}$ in winter. Lack of direct observations makes model results difficult to evaluate. For winter, the only available, substantial data set is from the Surface Heat Budget of the Arctic Ocean (SHEBA) experiment (Uttal et al. 2002) while for summer, observations from several research cruises are obtained; for example, in addition to SHEBA, the Arctic Ocean Experiment 2001 (AOE-2001) and the Arctic Summer Cloud Ocean Study (ASCOS); see Tjernström et al. (2012) for a summary. Long data records are only available from the ice while evaluations over open water are difficult.

A comparison to ERA-Interim shows that the difference is near zero over large parts of the Arctic, as expected for the sea-ice dominated central parts of the Arctic. Larger differences, up to $\pm \sim 50 \mathrm{~W} / \mathrm{m}^{2}$, appear in large organized structures over the northern North-Atlantic and the Nordic Seas, where they reflect differences in ice conditions and SST. In particular the large north-south elongated (e) RCP 8.5

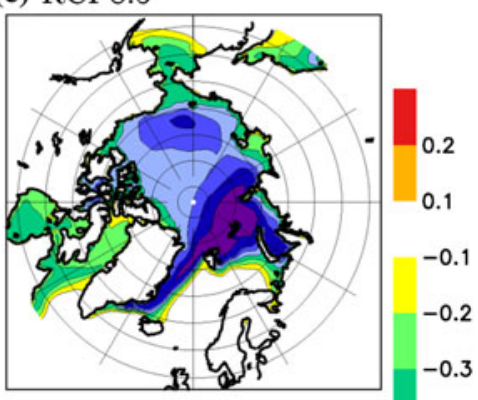

(h) RCP4.5, JJA

(i) $\mathrm{RCP} 4.5$, SON
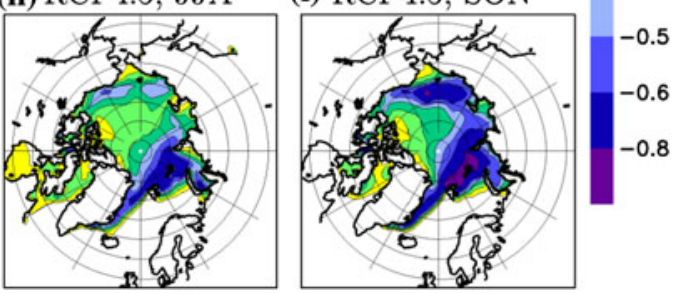

RCP8.5 (e). f-i Seasonal mean sea ice concentration changes between 2080-2099 and 1980-1999 in RCP4.5. Shown are ensemble means. Note that there is only one RCP2.6 simulation

difference in the Greenland Sea is a direct reflection of a shift in the ice edge between the observations and EC-Earth (compare Fig. 4).

The modeled winter sensible heat flux is reasonable compared to the SHEBA observations. The probability density function (PDF) of modeled fluxes (not shown) is skewed, with a peak at $-10 \mathrm{~W} / \mathrm{m}^{2}$, a negative tail to $\sim-50 \mathrm{~W} / \mathrm{m}^{2}$ and a sharper cut-off around $10 \mathrm{~W} / \mathrm{m}^{2}$. The observed PDF is wider, from about -30 to $20 \mathrm{~W} / \mathrm{m}^{2}$ with a flat peak around $-5 \mathrm{~W} / \mathrm{m}^{2}$. While the modeled median summer sensible heat flux is also reasonable, the PDF-width is a factor of $2-3$ too large; $\pm 20-30 \mathrm{~W} / \mathrm{m}^{2}$ in the model and $\pm \sim 10 \mathrm{~W} / \mathrm{m}^{2}$ in the observations. The modeled latent heat fluxes are too large in both seasons. In winter, modeled values are relatively normally distributed $\left(\sim \pm 10 \mathrm{~W} / \mathrm{m}^{2}\right)$ while in summer the distribution is skewed, from -10 to $20-30 \mathrm{~W} / \mathrm{m}^{2}$ with a peak around zero. Observations indicate zero fluxes in winter and a skewed distribution in summer, also with a peak at zero but only 
Fig. 5 Annually averaged fluxes of sensible and latent heat flux for 1980-1999 in EC-Earth (a and b, respectively) and difference between EC-Earth and ERA-Interim (c and d, respectively). The EC-Earth annually averaged change between 2080-2099 and 1980-1999 in sensible (e and $\mathbf{g}$ ) and latent heat flux (f and $\mathbf{h}$ ) under the RCP4.5 (e and f) and RCP8.5 (g and h) emission scenarios. Upward fluxes are positive, all values are in $\mathrm{W} / \mathrm{m}^{2}$. Note the differences in color bars
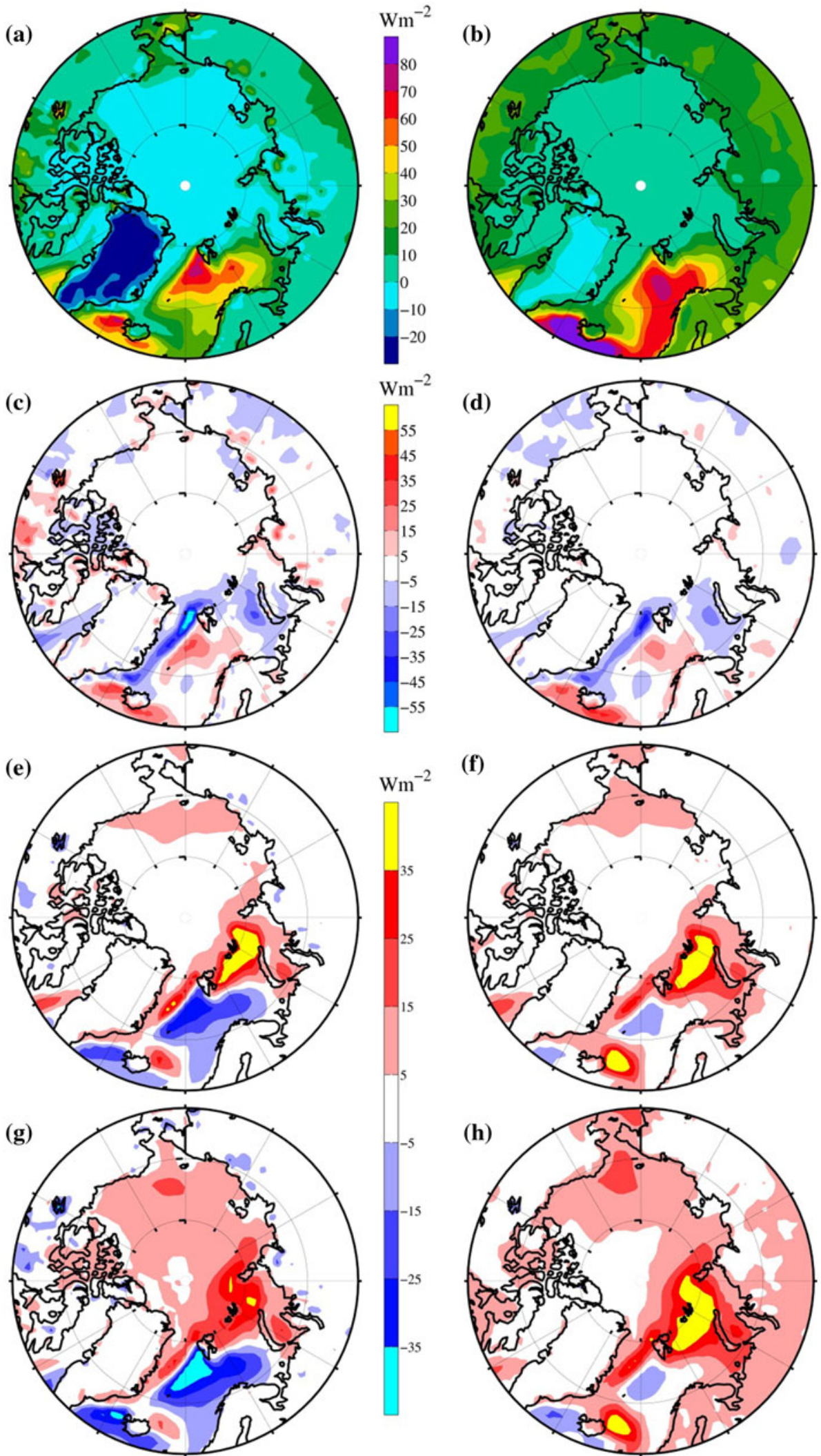
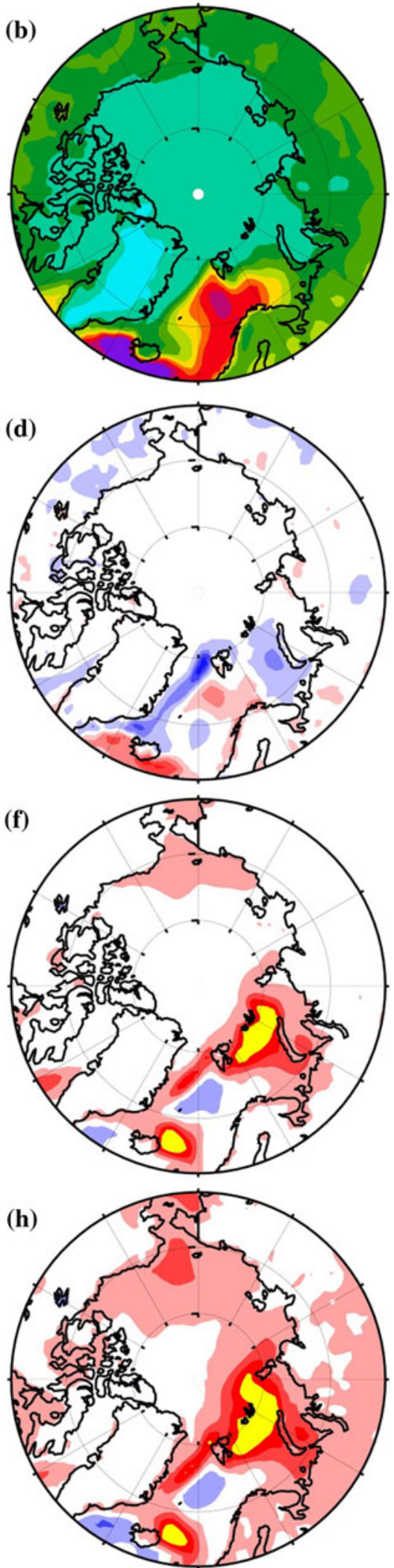
Fig. 6 Median annual cycles of $\mathbf{a}, \mathbf{b}$ sensible and $\mathbf{c}, \mathbf{d}$ latent heat flux, for (blue) 1980-1999, and the (yellow) RCP4.5 and (red) RCP8.5 emission scenarios (2080-2099), analyzed separately for (a and c) icecovered and (b and d) open ocean areas north of $70^{\circ} \mathrm{N}$. Thick line is the ensemble average median while the thin lines are for the three ensemble members; all values are in $\mathrm{W} / \mathrm{m}^{2}$. The bottom sub-panels indicate the percentage of the total number of grid points (land included) considered (left) icecovered and (right) open ocean. Upward fluxes are positive. See the text for a discussion
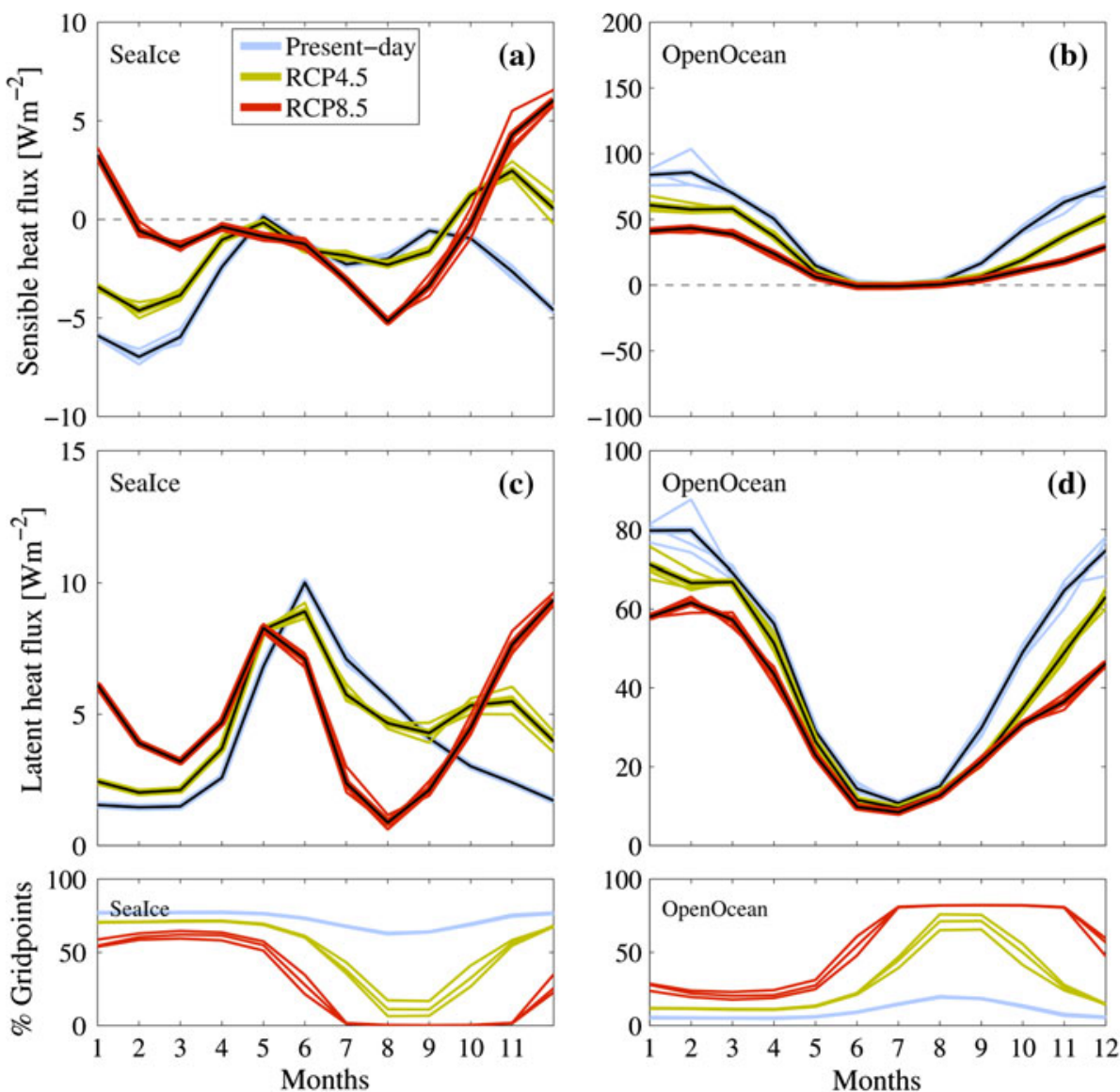

from minus a few to $\sim 5 \mathrm{~W} / \mathrm{m}^{2}$. Both heat fluxes over open water, as expected, are large in winter (up to $100-200 \mathrm{~W} / \mathrm{m}^{2}$ ) while in summer they are smaller, similar to the fluxes over the ice. Largely, the turbulent heat fluxes in EC-Earth are in good agreement with the CMIP3 model ensemble (Sorteberg et al. 2007).

The most extreme positive and negative local changes in the sensible heat fluxes under the lower emission scenarios are similar and reach $\pm 35 \mathrm{~W} / \mathrm{m}^{2}$ (Fig. 5e). In the highest emission scenario, the annually averaged changes do not grow proportionally (Fig. $5 \mathrm{~g}$ ). The primary reason for the changes seems to be related to the retreating northern North Atlantic sea-ice edge during winter. The changes are small in other parts of the Arctic Ocean. The change pattern has a large upward flux along the ice edge with a corresponding negative change further to the south. The high upward fluxes are due to winter cold-air outbreaks over the relatively warm open ocean that is shifting northward with the ice edge. In the RCP8.5 scenario (Fig. $5 \mathrm{~g}$ ) there is an additional small $\left(5-15 \mathrm{~W} / \mathrm{m}^{2}\right)$ widespread increase over the sea-ice area, which is dominated by winter conditions and is likely due to the ice thinning or more leads and lower sea ice concentrations.
Changes in the latent heat flux exhibit a small maximum east of Iceland and a larger area with increased fluxes in the Barents Sea, extending into the Kara Sea (Fig. 5f, h). Maximum changes reach $35-40 \mathrm{~W} / \mathrm{m}^{2}$, approximately constant across emission scenarios. Instead the area of the maxima increases with emissions. A slight decrease in the upward flux over the Greenland Sea remains essentially unchanged. The latent heat fluxes also exhibit a widespread increase in the annual average upward flux over the central Arctic Ocean, dominated by winter conditions. Unlike the sensible heat flux, the summer latent heat flux over the central Arctic Ocean shows a small but widespread decrease $\left(\sim 5-10 \mathrm{~W} / \mathrm{m}^{2}\right)$.

Figure 6 shows annual cycles of the median values of area averaged 3 hourly sensible and latent heat fluxes, for the present climate and two emission scenarios, analyzed separately for sea-ice and open-water grid points using a threshold at an ice fraction of $50 \%$. Note that for the RCP8.5 scenario there is little ice left in summer. However, as long as there is ice left in a grid box, even at appreciably $<50 \%$, it will still affect the thermodynamics near the surface.

For the present climate sensible heat flux over sea ice (Fig. 6a), median values are negative in winter, at 
about $-6 \mathrm{~W} / \mathrm{m}^{2}$, and near zero in May through September, while the latent heat fluxes (Fig. 6c) are small and positive in winter and peak at $10 \mathrm{~W} / \mathrm{m}^{2}$ in June. The annual cycles exhibit significant changes for the different emission scenarios. For the highest emission scenario, the sensible heatflux cycle even reverses sign, to a weak upward flux in winter and a comparable downward flux in summer. Changes in the annual cycle of the latent heat flux over sea ice is more complex with dual peaks for the RCP8.5 in December and May, at almost 10 and $\sim 8 \mathrm{~W} / \mathrm{m}^{2}$, respectively; the near-zero minimum occurs in August. The amplitudes of the annual cycles over open water are reduced for both fluxes. The present-day maxima in December at $\sim 80 \mathrm{~W} / \mathrm{m}^{2}$ are reduced to about 45 and $60 \mathrm{~W} / \mathrm{m}^{2}$ in sensible and latent heat flux, respectively while summer values are unchanged.

We offer the following interpretation of these results. In the present climate, conditions in winter are dominated by sea ice leading to dry and cold air in the lower troposphere and consequently small latent and predominately downward sensible heat fluxes. As this air is advected over warm open water, either over leads or open ocean, the contrast is large and the resulting fluxes are large and upward. As ice fractions gradually diminish, cold and dry over-ice conditions gradually become less dominant and the air-mass transforms to open-ocean maritime conditions. For the highest emission scenarios in summer, large open-water areas will dominate; air advected over what little ice is left becomes moist and warm and the fluxes are therefore small or even downward.

Again, note that the annual cycles in Fig. 6 are derived over sea-ice covered ocean and open ocean separately. We do this in an attempt to better understand the physical processes responsible for the change. If we instead consider the annual cycles in turbulent surface fluxes for the whole Arctic Ocean region (i.e. disregarding surface type) the future scenarios show unchanged fluxes during summer and increasing fluxes during the remaining part of the year (not shown). This increase is explained by the retreat of sea-ice in the future scenarios and that sea-ice is associated with substantially lower surface fluxes than open ocean (Fig. 6).

\subsection{Atmospheric temperature}

In the twentieth century, the annually averaged 2-m air temperature (T2m, Fig. 7a) is about $2-3 \mathrm{~K}$ colder in EC-Earth compared to ERA-Interim-reanalysis (Fig. 7b) in most Arctic Ocean regions. In regions with to much ice, particularly over the East Greenland Current (EGC), and over Alaska it is up to $6 \mathrm{~K}$ colder. Over north-western Canada, the model is $1-4 \mathrm{~K}$ warmer than the reanalysis. Chapman and Walsh (2007) found a similar cold bias in the
Arctic for the ensemble mean of 14 AR4-models but with a much larger cold bias in the Barents Sea. A recent study by de Boer et al. (2012) shows an Arctic wide cold bias of slightly below $2 \mathrm{~K}$ in the AR5-model CCSM4.

The simulated $\mathrm{T} 2 \mathrm{~m}$ changes in EC-Earth in the future (Fig. 7c-e) are strongly related to the changes in sea ice and heat fluxes, which agrees well to observations of the last decades (Screen and Simmonds 2010a). In RCP2.6, the warming in the twenty-first century is mainly concentrated on the Barents Sea region and surroundings. Here, annually averaged $\mathrm{T} 2 \mathrm{~m}$ increases by up to $10 \mathrm{~K}$ until the end of the twenty-first century. Over most land masses, the warming is not exceeding $2 \mathrm{~K}$. In RCP4.5, the warming reaches 2-5 K over land and 4-10 K over the Arctic Ocean, over the Barents Sea up to $15 \mathrm{~K}$. In RCP8.5, the warming north of $60^{\circ} \mathrm{N}$ is almost everywhere exceeding $6 \mathrm{~K}$ and the temperature increase over the Arctic Ocean is more than $10 \mathrm{~K}$; up to $17 \mathrm{~K}$ over the Barents Sea. In all scenarios, the temperature change is significant at the $95 \%$ significance level and the inter-ensemble variations are small compared to the change signal.

The temperature increase depends strongly on the season (Fig. 7f-i) and is largest in winter and autumn but with a different change pattern: the warming is more uniformly distributed in autumn while in winter it is particularly pronounced over the Barents Sea. The warming is smallest in summer because the surface stays near $0{ }^{\circ} \mathrm{C}$ until almost all sea ice has been melted. Only in RCP8.5, some Arctic Ocean regions warm up in summer due to the earlier onset of the sea ice melt period. The simulated temperature change in EC-Earth over the Arctic Ocean is at the upper end compared to the AR4-model ensemble but agrees rather well over land (Chapman and Walsh 2007). Note that the AR4-simulations were based on different emission scenarios than our AR5-simulations.

The winter (DJF) and summer (JJA) Arctic mean nearsurface temperatures (spatial mean for $70-90^{\circ} \mathrm{N}$ ) are shown in Fig. 8. The mean Arctic T2m at the end of the twentieth century is about 3 and $2 \mathrm{~K}$ colder in EC-Earth than ERAInterim in winter and summer, respectively. The warming in the twenty-first century is much more pronounced in winter and reaches 5, 8 and $18 \mathrm{~K}$ in RCP2.6, RCP4.5 and RCP8.5, respectively. In summer, the temperature increase is typically below a few degrees, reaching as much as $5 \mathrm{~K}$ only for the RCP8.5 scenario. The annual mean Arctic T2m change reaches up to $12 \mathrm{~K}$ in RCP8.5, which is slightly above the values found in CCSM4 for the same region in RCP8.5 (Vavrus et al. 2011). The interannual variability is much larger in winter than in the summer, as expected, in both model and ERA-Interim. The natural variability is also substantial in winter, when the difference between the ensemble members can reach several degrees and persists over decadal time scales. Although these differences are 
(a) $\mathrm{T} 2 \mathrm{~m}, 1980-1999$

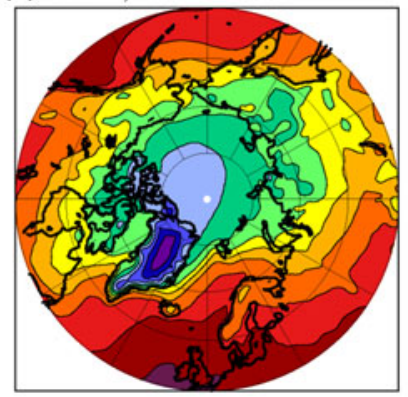

(b) EC-Earth - ERA-int, 1980-1999
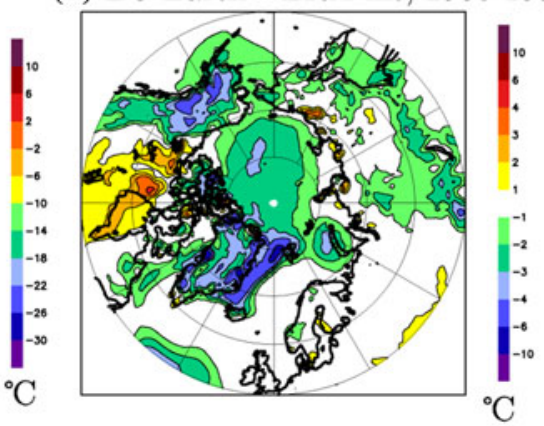

Change between 2080-2099 and 1980-1999

\section{(c) RCP2.6}

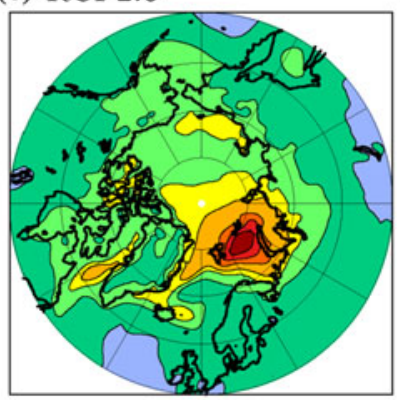

(d) $\mathrm{RCP} 4.5$

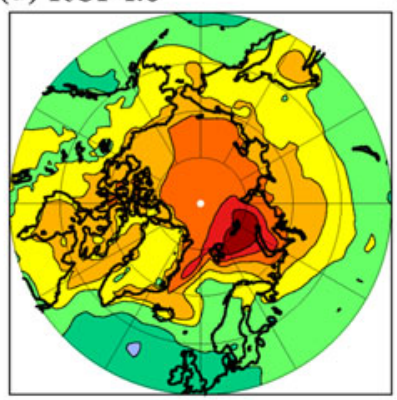

(e) $\mathrm{RCP} 8.5$

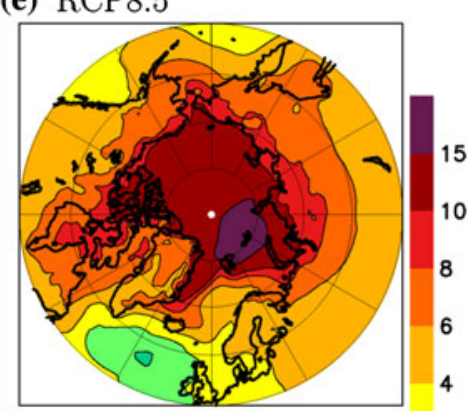

(f) RCP4.5, DJF

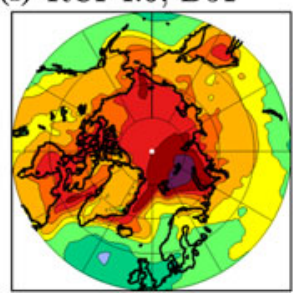

(g) RCP4.5, MAM

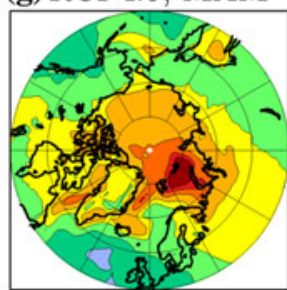

Fig. 7 a Annual mean two meter air temperature in ${ }^{\circ} \mathrm{C}$ in EC-Earth, averaged over 1980-1999 and b difference to ERA-Interim reanalysis. c-e Change in annual mean $2 \mathrm{~m}$ air temperature between 2080-2099 and 1980-1999 in RCP2.6 (c), RCP4.5 (d) and RCP8.5 (h) RCP4.5, JJA

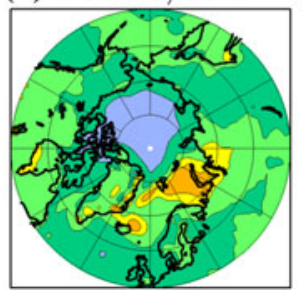

(i) $\mathrm{RCP} 4.5, \mathrm{SON} \quad 3$

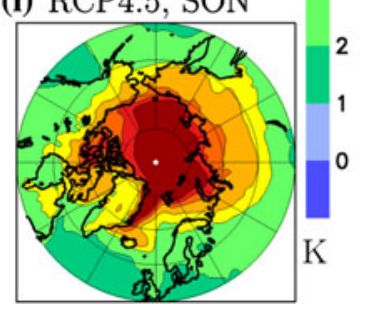
Note that there is only one RCP2.6 simulation

(e). f-i Seasonal mean $2 \mathrm{~m}$ air temperature changes between 2080-2099 and 1980-1999 in RCP4.5. Shown are ensemble means.

Fig. 8 Summer (JJA, dashed) and winter (DJF, solid) mean 2 m air temperature in ${ }^{\circ} \mathrm{C}$ averaged over $70-90^{\circ} \mathrm{N}$ in the twentieth century simulations (black), RCP4.5 (blue), RCP8.5 (red), RCP2.6 (green) with EC-Earth and the ERA-Interim reanalysis (stars)
$2 \mathrm{~m}$ air temperature, $70-90 \mathrm{~N}$

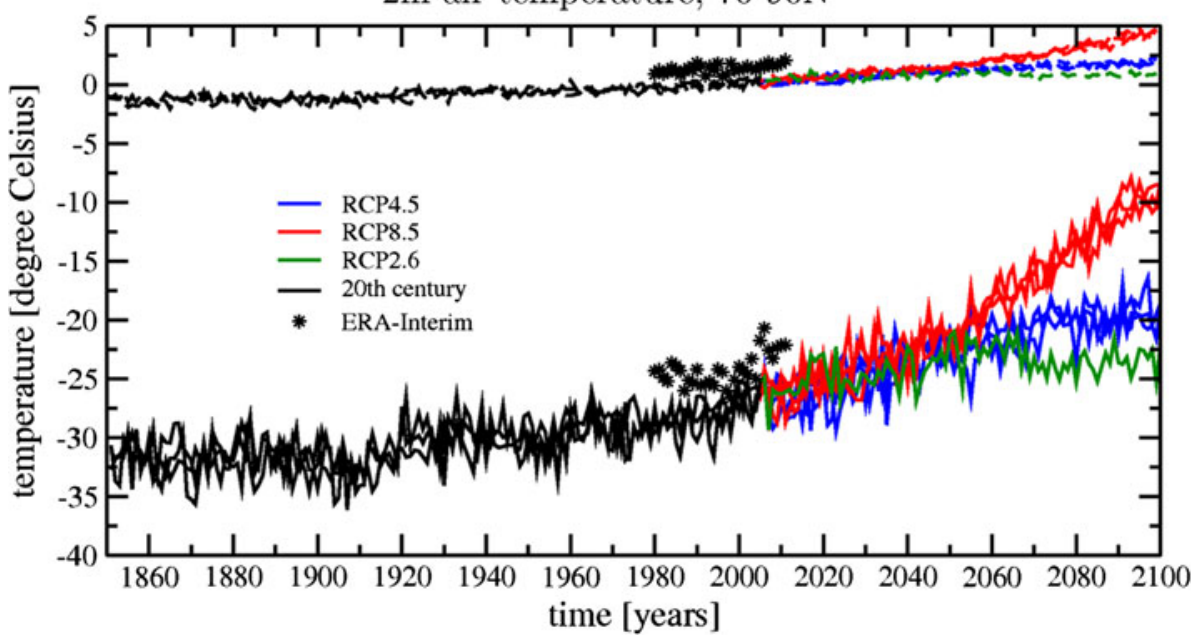


small compared to the change-signal, a larger ensemble size would reduce the uncertainties due to internal variations. The decadal scale variations also indicate enhanced decadal predictability for winter temperatures.

The zonally mean vertical temperature distribution is dominated by a strong winter near surface inversion in the high Arctic in the twentieth century (Fig. 9a). The warmest average temperatures typically occur at about $850-900 \mathrm{hPa}$. At the surface, the temperature is up to $6 \mathrm{~K}$ colder than the air aloft, primarily due to the effect of the negative net radiation at the surface. Over the Arctic Ocean, the insulating properties of the sea ice and snow also play an important role. In summer (Fig. 9b), on average, no temperature inversion is simulated by the model but the temperature decrease with height is relatively small compared to lower latitudes. The vertical temperature distribution compares well to the ERA-Interim reanalysis (Fig. 9c, d). The cold bias in the Arctic in EC-Earth is slightly reduced with increased height. Also the spatial pattern of the inversion strength in EC-Earth during winter compares well to the ERA-Interim reanalysis (not shown) and is smaller and thus more realistic than in most CMIP3 models (Medeiros et al. 2011).

The simulated future changes differ distinctively between summer and winter (Fig. 9e-j). In summer, the atmosphere is relatively uniformly warmed by about $0-2 \mathrm{~K}$ in RCP2.6, $1-3 \mathrm{~K}$ in RCP4.5 and $3-6 \mathrm{~K}$ in RCP8.5. The warming near the surface is slightly reduced north of $80^{\circ} \mathrm{N}$ because of the melting sea ice and the cold ocean. In winter, the warming near the surface is strongly amplified compared to lower latitudes. The temperature amplification decreases with increasing height and above $600 \mathrm{hPa}$, no amplification can be found. Thus, the Arctic atmosphere becomes less stable during winter; in RCP8.5 the winter temperature inversion totally disappears at the end of the twenty-first century. This vertical warming distribution agrees well to the trend in ERA-Interim reanalysis data (Screen and Simmonds 2010b).

\subsection{Sea level pressure}

The sea level pressure (SLP) in the twentieth century (Fig. 10a) is well simulated in the Arctic compared to ERA-Interim reanalysis (Fig. 10b) and biases are small compared to most other global climate models (Chapman and Walsh 2007; de Boer et al. 2012). In an area from Alaska across the Bering Strait towards Siberia, the annually averaged SLP is underestimated by $1-3 \mathrm{hPa}$. Over the European Arctic, the SLP is overestimated by $1-2 \mathrm{hPa}$.

The change of SLP in the twenty-first century (Fig. 10c-e) is small in RCP2.6; mostly within the range of $\pm 1 \mathrm{hPa}$ and only in parts of the Barents Sea and Bering Sea significant at the $95 \%$-significance level. Here, where the ice margins move northward, the decrease reaches 1.5 and $2 \mathrm{hPa}$, respectively. In RCP4.5, the largest SLP reductions occur in the Barents Sea, and north of Greenland with up to $3 \mathrm{hPa}$. SLP is slightly decreased over most of the Arctic Ocean and the American Arctic land masses and slightly increased over the northeastern North Atlantic and northwestern Europe. In RCP8.5, the change pattern is similar but the amplitude is substantially larger than in RCP4.5. The anomalous pressure gradient across the sub-polar North Atlantic causes anomalously southwesterly winds here. The ensemble mean changes in RCP4.5 and RCP8.5 are significant in most of the Arctic but compared to most other Arctic parameters, the SLP change signal varies relatively strong between members. While the spatial change pattern over the Arctic Ocean is relatively robust, the SLP increase over the North Atlantic varies substantially across model members. Also Deser et al. (2012) showed that the SLP-change signal shows a high spread between model members. Most AR4-models show a similar decrease in SLP over the Arctic in the twenty-first century and many of them also show maximum decreases in the Bering Strait and/or the Barents Sea regions. However, in contrast to EC-Earth, most AR4 models also show a SLP reduction over western and middle Siberia (Chapman and Walsh 2007). SLP change patterns in RCP8.5 simulations with CCSM4 (Vavrus et al. 2011) are similar to our RCP8.5 pattern but their amplitude is about $50 \%$ smaller.

\subsection{Precipitation and evaporation}

The precipitation in EC-Earth in the twentieth century (Fig. 11a) is about 10-30 \% smaller over the Arctic Ocean compared to the ERA-Interim reanalysis (Fig. 11b); over Alaska, parts of Siberia and the north eastern Atlantic and northern Europe, there is $10-30 \%$ more precipitation in EC-Earth. Serreze and Hurst (2000) compared ERAreanalysis to existing Arctic precipitation data sets and concluded that ERA realistically simulates precipitation over most of the Arctic except for the Atlantic sector where precipitation is somewhat underestimated. Note, that also data sets of precipitation over the Arctic Ocean have large uncertainties due to coarse resolution of observations in space and time and gauge undercatchment issues.

All scenario simulations show a general increase of precipitation in the entire Arctic except for small areas in the Nordic Seas (Fig. 11c-e). The increase is largest in the Barents Sea, Greenland's southeast coast and the south coast of Alaska; up to more than $300 \mathrm{~mm} /$ year in all RCPs. In the Central Arctic, precipitation changes strongly differ with the scenario; the increase is about $20 \mathrm{~mm} / \mathrm{year}$ in RCP2.6 and up to $100-150 \mathrm{~mm} /$ year in RCP8.5. Over a number of land regions and in parts of the Beaufort Sea, the 
(a) EC-Earth: T, DJF, 1980-1999

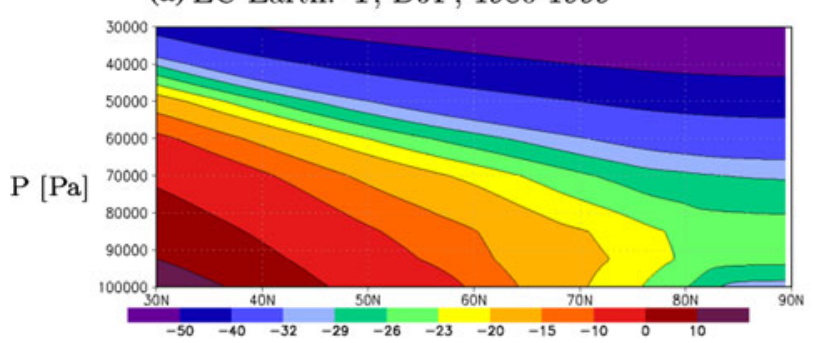

(c) ERA-Int: T, DJF, 1980-1999

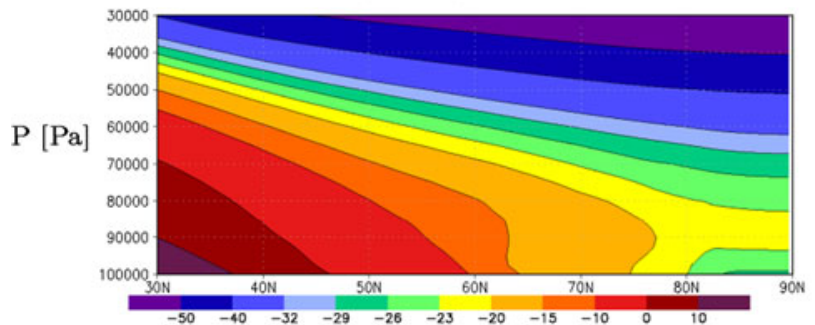

(e) RCP2.6, DJF, 2080-2099 - 1980-1999

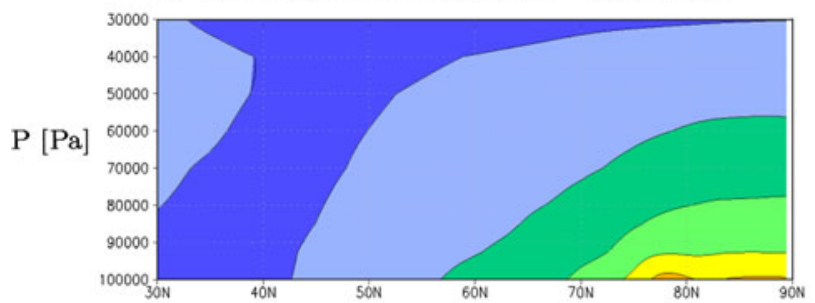

(g) RCP4.5, DJF, 2080-2099 - 1980-1999

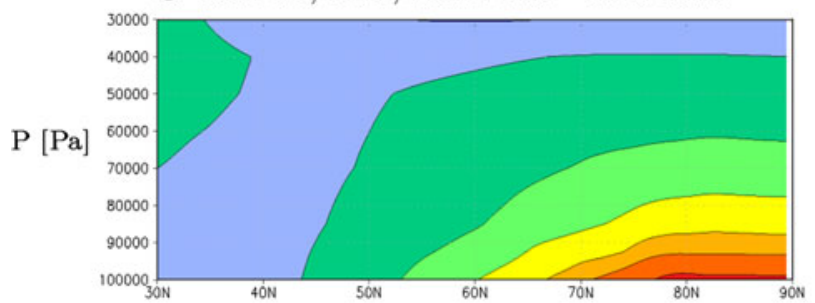

(i) RCP8.5, DJF, 2080-2099 - 1980-1999
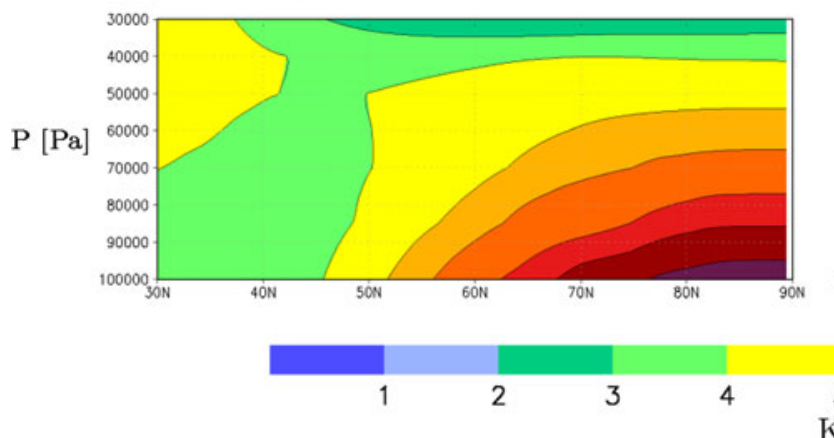

Fig. 9 Vertical temperature distribution $\left(\right.$ in ${ }^{\circ} \mathrm{C}$ ) as a function of latitude in winter (DJF, a) and summer (JJA, b) averaged over 1980-1999 in the twentieth century simulations with EC-Earth and ERA-Interim reanalysis $(\mathbf{c}, \mathbf{d})$. e, $\mathbf{f}$ Changes in winter and summer in (b) EC-Earth: T, JJA, 1980-1999

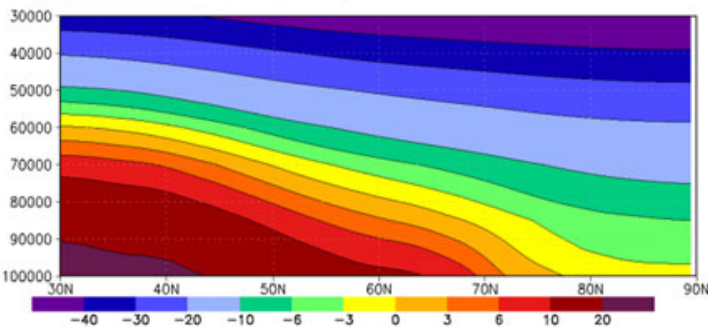

(d) ERA-Int: T, JJA, 1980-1999

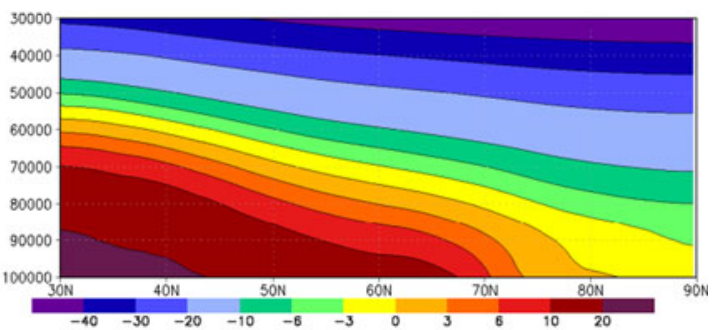

(f) RCP2.6, JJA, 2080-2099 - 1980-1999

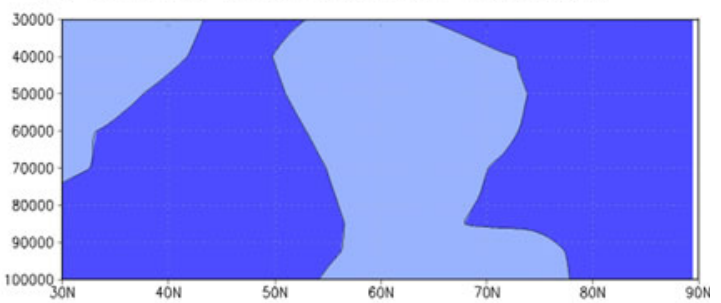

(h) RCP4.5, JJA, 2080-2099 - 1980-1999

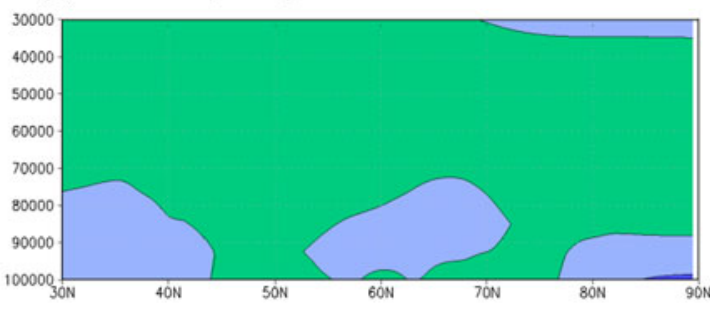

(j) RCP8.5, JJA, 2080-2099 - 1980-1999

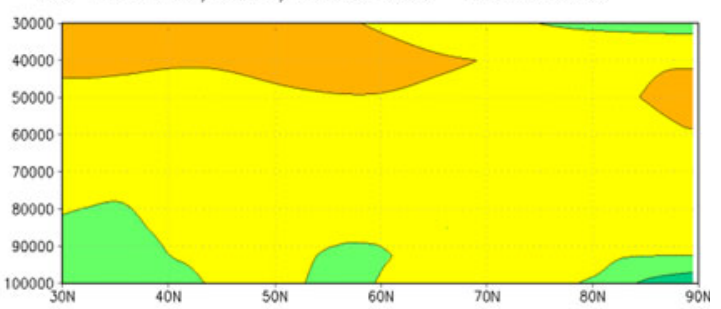

$\begin{array}{lllll}5 & 6 & 8 & 10 & 15 \\ K & & & \end{array}$

RCP2.6 between 2080-2099 and 1980-1999. g, h Same as e and f but for RCP4.5. (i) and (j) Same as $\mathbf{e}$ and $\mathbf{f}$ but for RCP8.5. Shown are ensemble means except for RCP2.6 
(a) SLP, 1980-1999

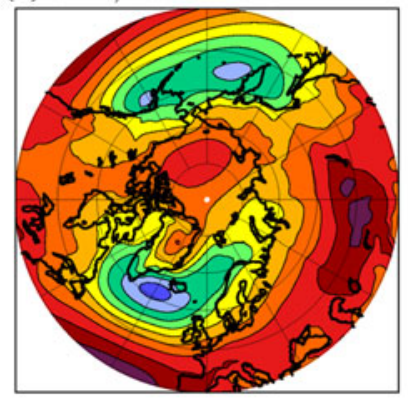

Change between 2080-2099 and 1980-1999 (b) EC-Earth - ERA-int, 1980-1999

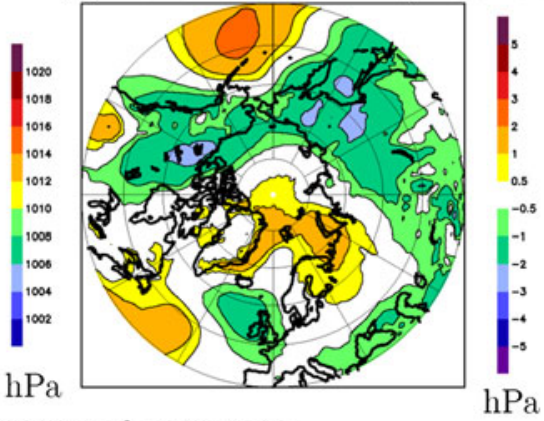

(c) $\mathrm{RCP} 2.6$

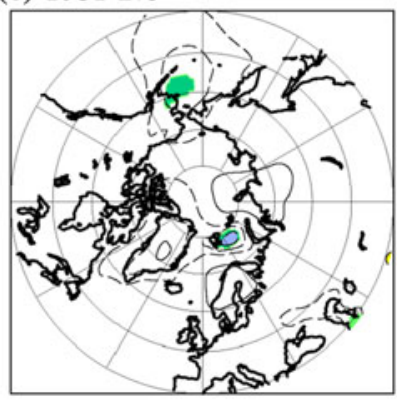

(d) RCP4.5

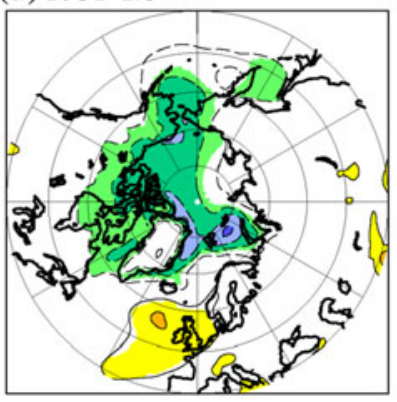

(e) $\mathrm{RCP} 8.5$

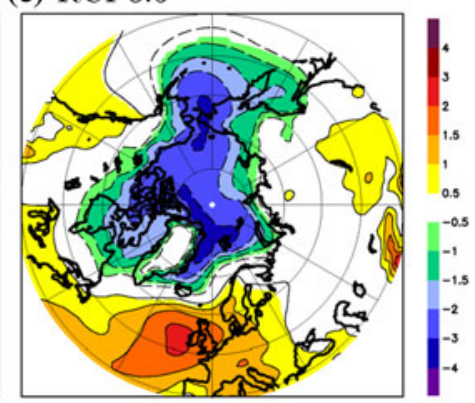

Fig. 10 a Annual mean SLP in hPa in EC-Earth, averaged over 1980-1999 and b difference to ERA-Interim reanalysis. $\mathbf{c}-\mathbf{e}$ Change in annual mean SLP between 2080-2099 and 1980-1999 in RCP2.6 (c),
RCP4.5 (d) and RCP8.5 (e). Shown are ensemble means. Note that there is only one RCP2.6 simulation. The ensemble mean SLP-change is significant at the $95 \%$ significance level in all colored areas (a) precipitation, $1980-1999$

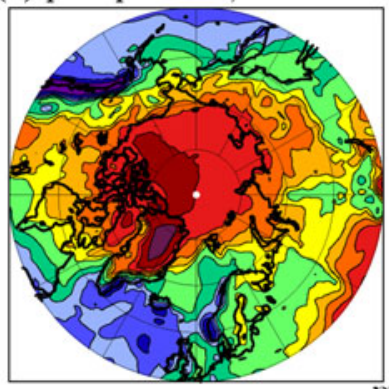

(b) EC-Earth - ERA-int, 1980-1999
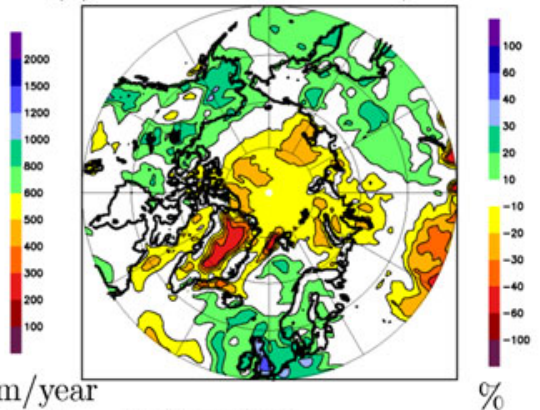

Change between 2080-2099 and 1980-1999

(c) RCP2.6

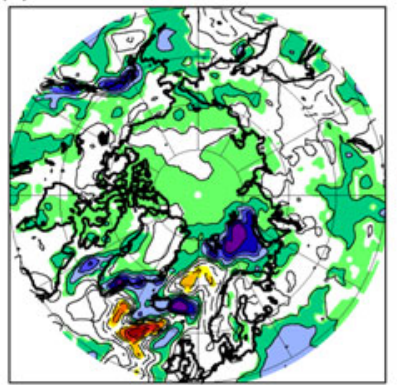

(d) RCP4.5

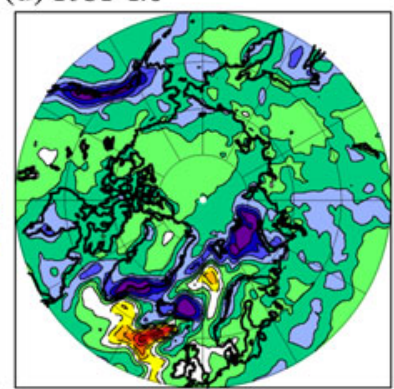

(e) RCP8.5

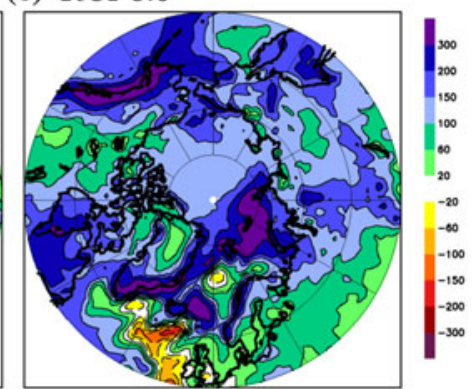

$\mathrm{mm} /$ year

Fig. 11 a Annual mean precipitation in $\mathrm{mm} / \mathrm{year}$ in EC-Earth, averaged over 1980-1999 and b difference to ERA-Interim reanalysis in \%. c-e Change in annual mean precipitation between 2080-2099 and 1980-1999 in RCP2.6 (c), RCP4.5 (d) and RCP8.5 (e) in $\mathrm{mm} /$ year. Shown are ensemble means. Note that there is only one RCP2.6 simulation. The ensemble mean precipitation change is significant at the $95 \%$ significance level in all colored areas 
(a) Cloud amount

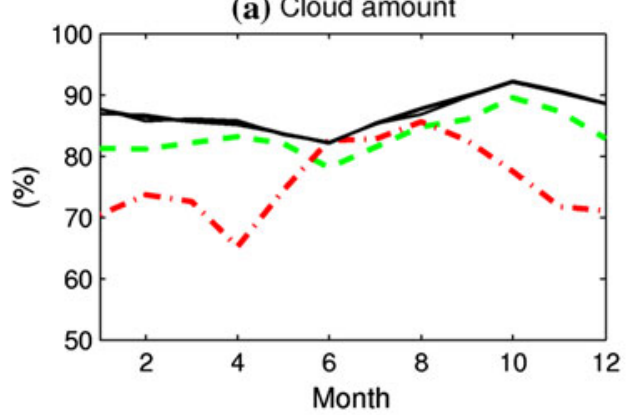

(c) Cloud condesate

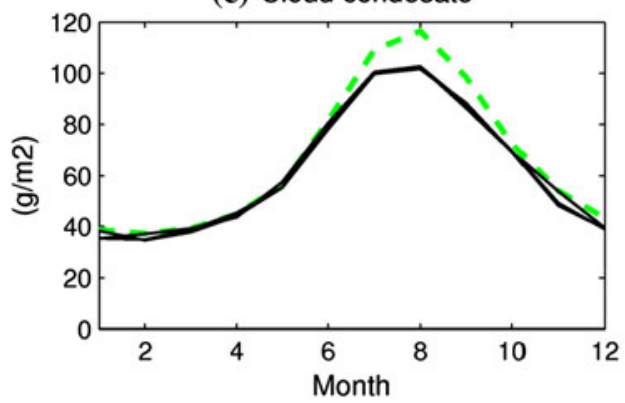

(e) LW CRF

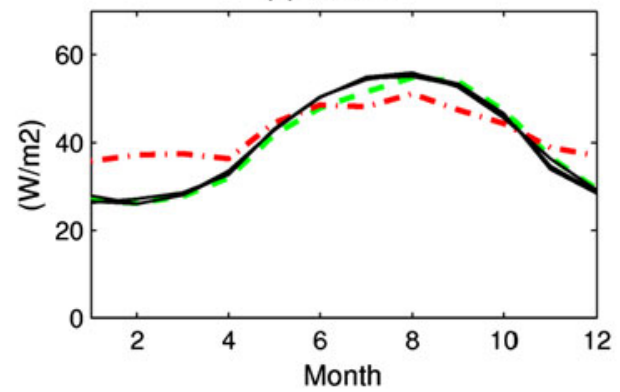

(g) SW CRF

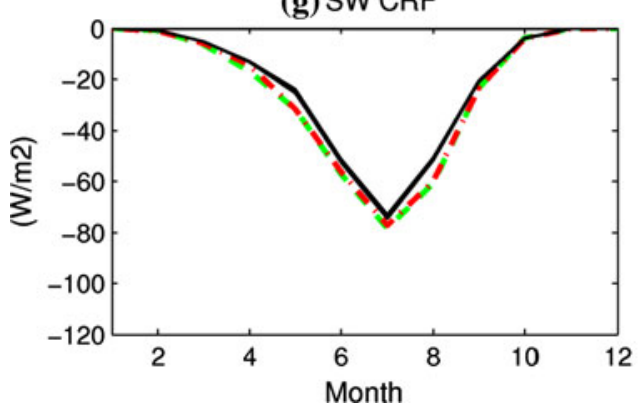

Fig. 12 Cloud variables averaged over $70-90^{\circ} \mathrm{N}$ : a mean cloud fraction, c total cloud water path, e LW CRF g SW CRF for the twentieth century simulations (black lines) in EC-Earth, ERA-Interim (green line), APP-X data (red line) and changes in the cloud variables

precipitation change is not significant at the $95 \%$-level in RCP2.6. Vavrus et al. (2011) found a comparable but spatially more uniform increase over the Arctic in CCSM4.

Evaporation over the Arctic Ocean is small in the twentieth century and reaches 20-50 mm/year (not shown). Over the Arctic land areas, evaporation reaches up to $400 \mathrm{~mm} /$ year and over the sea near the ice edge almost (b) Change in cloud amount

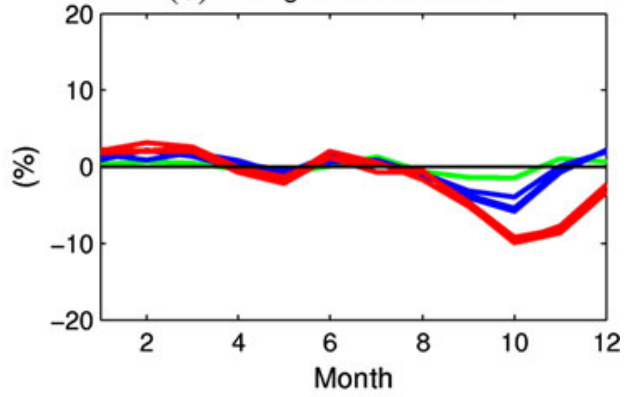

(d) Change in cloud condensate

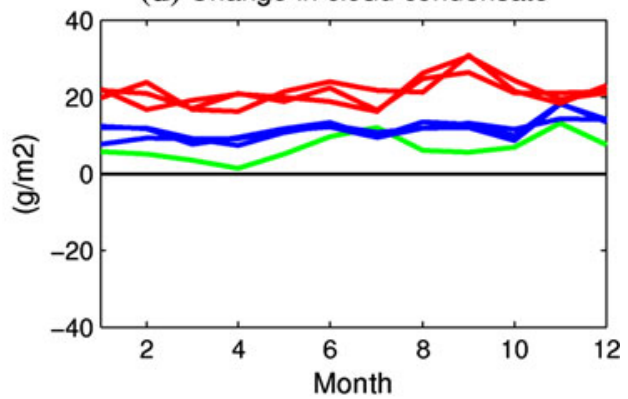

(f) Change in LW CRF

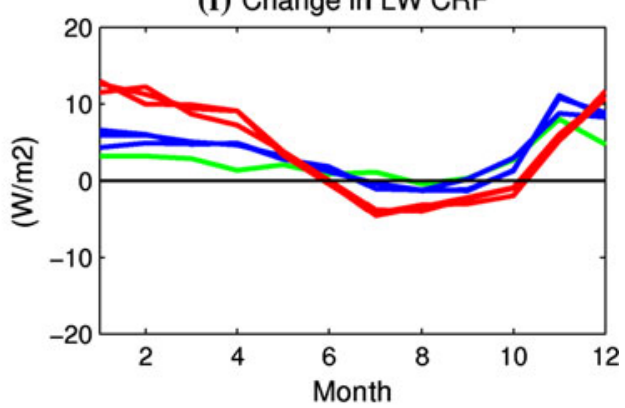

(h) Change in SW CRF

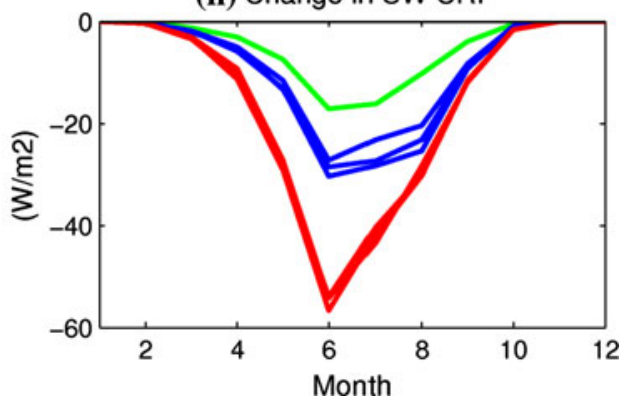

between 2080-2099 and 1980-1999 in EC-Earth: b mean cloud fraction, $\mathbf{d}$ total cloud water path, $\mathbf{f} \mathrm{LW}$ CRF and $\mathbf{h}$ SW CRF for all emissions scenarios RCP2.6 (green line), RCP4.5 (blue lines) and RCP8.5 (red lines)

$1,000 \mathrm{~mm} /$ year. Also for evaporation, observational data are uncertain. However, over land along $65^{\circ} \mathrm{N}$, observations suggest an annual mean evaporation between 200 and $350 \mathrm{~mm}$ (Serreze and Hurst 2000), which fits relatively well to EC-Earth. Precipitation in EC-Earth exceeds evaporation $(\mathrm{P}-\mathrm{E}>0)$ in most Arctic areas except for some smaller regions in the Nordic Seas. In the twenty-first 
Fig. 13 a Meridional atmospheric energy transport as function of latitude. Total (dark green), dry-static (light green), and latent transports (red) in EC-Earth (solid) and ERAInterim (dotted) averaged over 1980-1999. b Total (dark green) and latent transport changes (red) in EC-Earth between 2080-2099 and 1980-1999 for the 2.6 (dashed), 4.5 (dotted), and 8.5 (solid) RCP emission scenario. Latitudes where the statistical significance exceeds $95 \%$ is indicated by straight lines at the bottom. The colours and forms of these lines correspond to the transport curves. The statistical significance is estimated on the basis of a two-sided student's $t$ test (a) Meridional atmospheric energy transports, 1980-1999

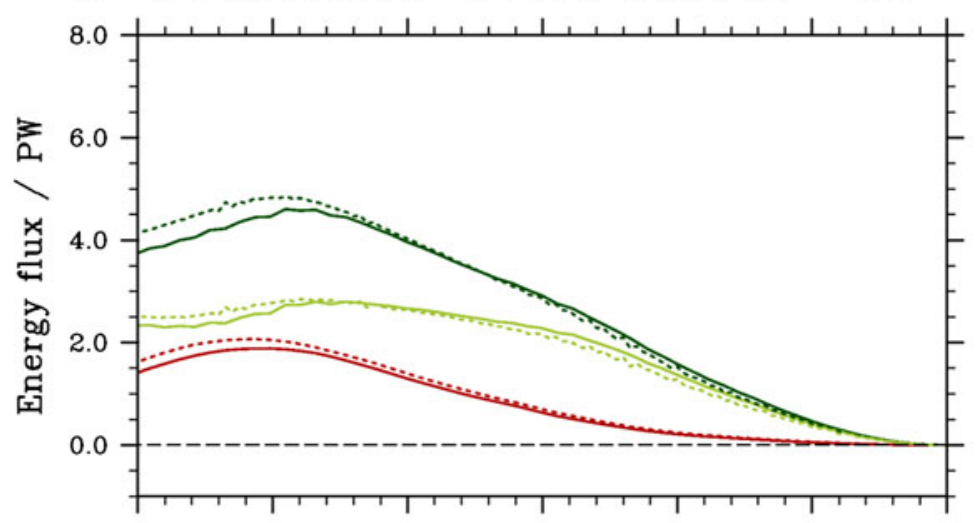

(b) Changes in energy transports, 2080-2099 - 1980-1999

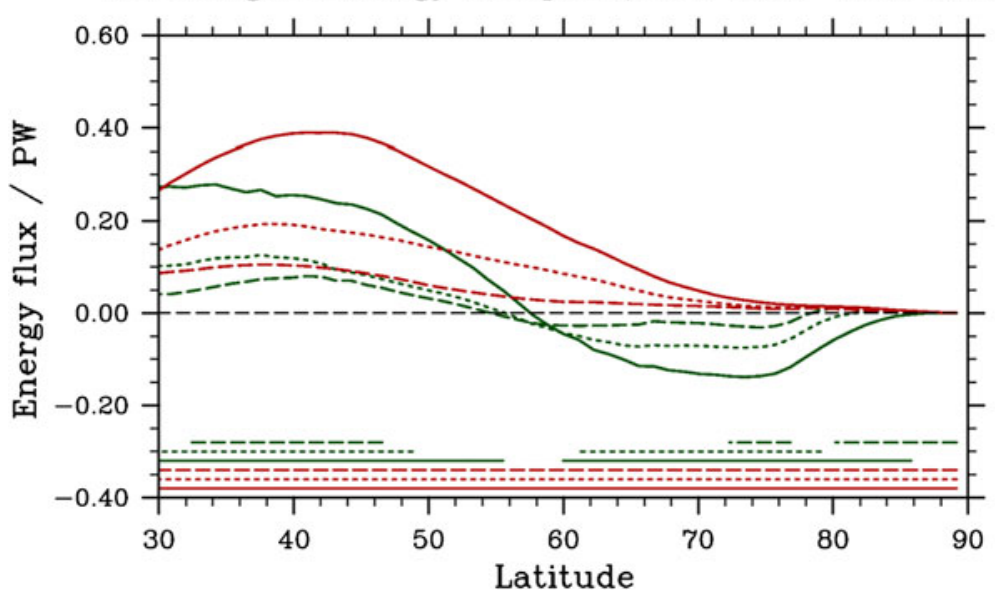

century, evaporation is strongly enhanced. The change pattern resembles the one of precipitation. Except for near the ice margins, where $\mathrm{P}-\mathrm{E}$ is near zero or even slightly negative, the change in $\mathrm{P}-\mathrm{E}$ is positive and slightly increasing with growing RCP.

\subsection{Cloudiness and radiative forcing}

EC-Earth twentieth century simulated cloud variables are compared to APP-x satellite estimates (Wang and Key 2005; Karlsson and Svensson 2011) and ERA-Interim analysis in Fig. 12 (left column). The three EC-Earth simulations and ERA-Interim annual cycles of cloud amount over the Arctic $\left(70-90^{\circ} \mathrm{N}\right)$ are very similar. In summer, EC-Earth and ERA-Interim are close to the APP-x cloud fraction of $84 \%$. In winter, EC-Earth overestimates cloud fraction by $15 \%$ and ERA-Interim by $10 \%$ compared to the observations. However, the cloud fractions are within the range of the substantial across-model spread found for CMIP3 models in Arctic winter (Vavrus et al. 2009; Karlsson and Svensson 2011). It should be emphasized that cloud fraction is not a very well defined variable in general and even more so in the Arctic where a substantial part of the clouds are optically very thin. The EC-Earth total cloud water path (TWP), the sum of the liquid water path (LWP) and ice water path (IWP), is at minimum in January at $40 \mathrm{~g} / \mathrm{m}^{2}$ (90\% IWP) and peaks in August at $100 \mathrm{~g} / \mathrm{m}^{2}$ (60\% LWP).

The longwave (LW) and shortwave (SW) surface cloud radiative forcings (CRFs) are calculated from the difference in all sky and clear sky net LW and SW fluxes at the surface. The LW warming by EC-Earth and ERA-Interim clouds varies from $20 \mathrm{~W} / \mathrm{m}^{2}$ in winter to $55 \mathrm{~W} / \mathrm{m}^{2}$ in summer. The slightly larger cloud fraction and less cloud condensate in EC-Earth compared to ERA-Interim result in very similar values of the LW CRFs (Fig. 12e). In winter, EC-Earth and ERA-Interim LW CRFs are $10 \mathrm{~W} / \mathrm{m}^{2}$ lower than the APP-X estimate. The modeled SW cloud cooling effect is strongest in July with $-70 \mathrm{~W} / \mathrm{m}^{2}$, about $5 \mathrm{~W} / \mathrm{m}^{2}$ less than for ERAInterim due to the smaller amount of cloud condensate in EC-Earth. EC-Earth total cloud forcing is positive from September to May with maximum warming in October, $\sim 45 \mathrm{~W} / \mathrm{m}^{2}$, and cooling in July, $-20 \mathrm{~W} / \mathrm{m}^{2}$, which is in good agreement to the APP-x data (not shown).

At the end of the twenty-first century, the changes in the cloud variables increase with increasing emission scenario 
(a) Meridional atmospheric energy transports, 1980-1999
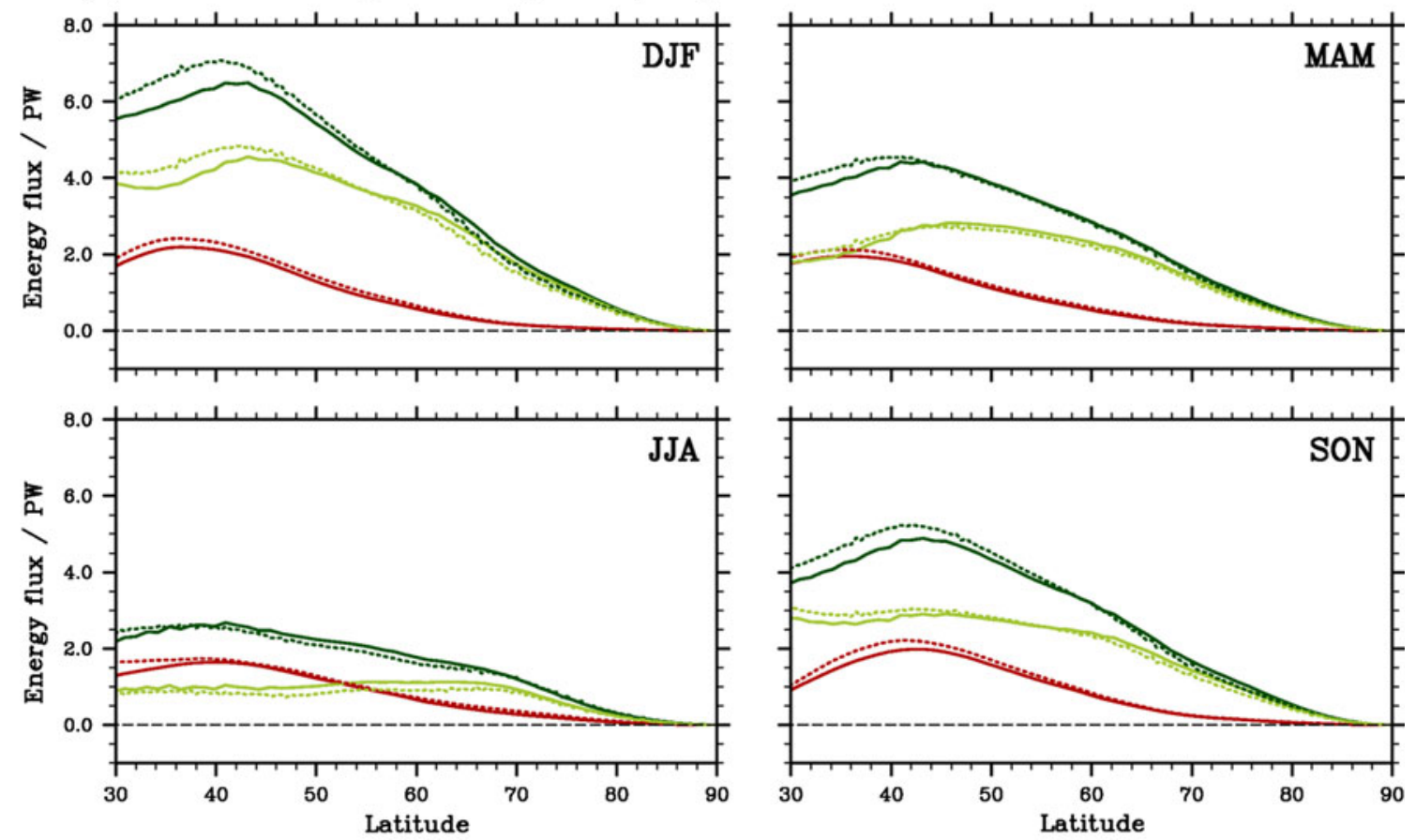

(b) Changes in energy transports, 2080-2099 - 1980-1999
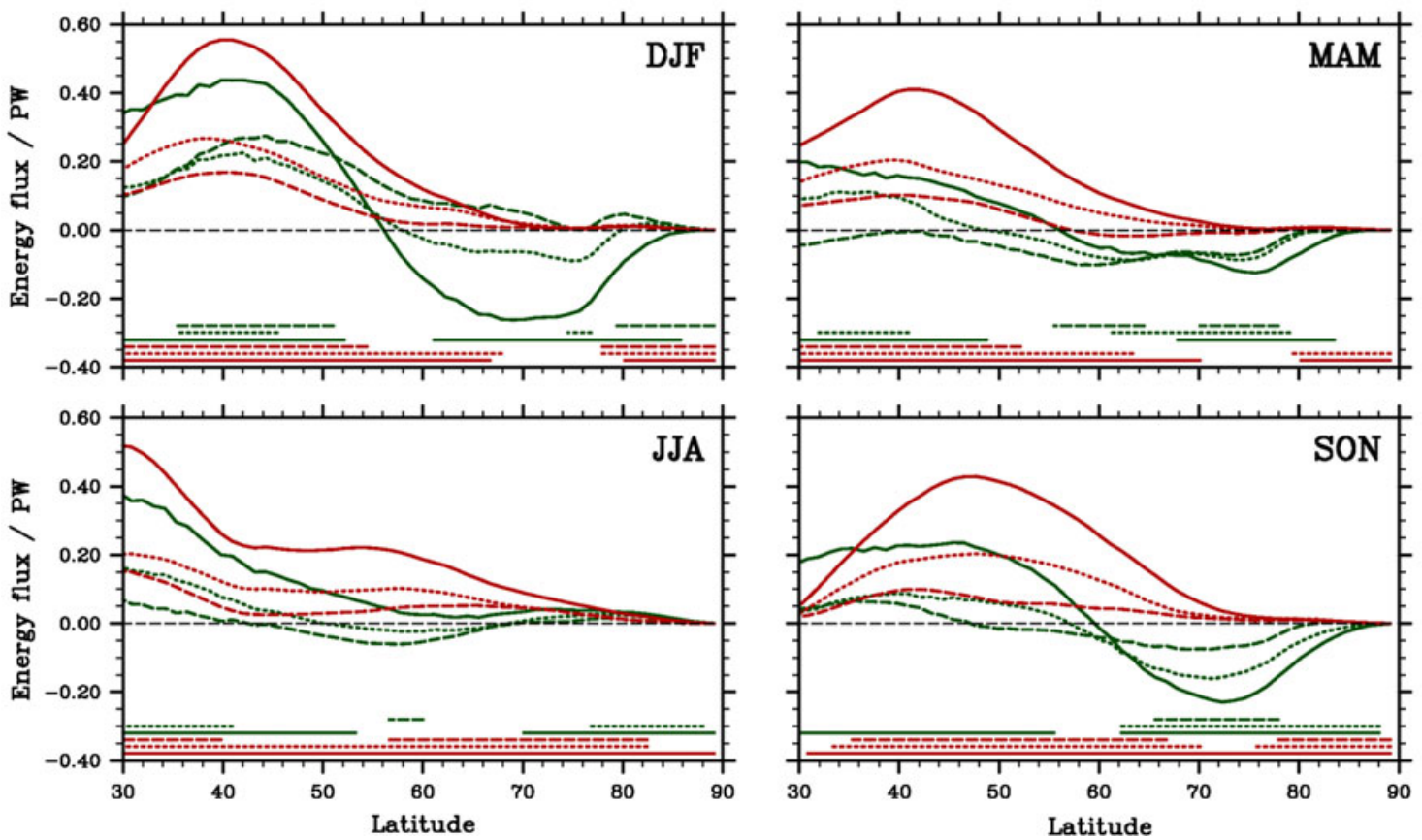

Fig. 14 a As (a) of Fig. 13 but split into the four seasons Dec-Feb (DJF) Mar-May (MAM), Jun-Aug (JJA), and Sep-Nov (SON). b As (b) of Fig. 13, but split into the four seasons Dec-Feb (DJF) Mar-May (MAM), Jun-Aug (JJA), and Sep-Nov (SON)

(Fig. 12, right column). The mean total cloud fractions increase a few percent in winter and spring due to increased cloudiness over the sea-ice while cloudiness is decreased over the Barents Sea region where the warming is the highest and the sea ice is strongly reduced. Vavrus et al.
(2009) analyzed the cloud fraction changes for 20 CMIP3 models for SRES A1B emission scenario and found an increase in the ensemble mean monthly cloud fractions all year $(4-5 \%$ in winter and $1-2 \%$ in summer). The ensemble mean change was dominated by models with low 
Fig. 15 a Ocean circulation and velocity (coloured) in $109 \mathrm{~m}$ depth in $\mathrm{m} / \mathrm{s}$ in a) twentieth century simulations (1980-1999), b RCP2.6 (2080-2099), c RCP4.5 (2080-2099) and d RCP8.5 (2080-2099) with EC-Earth. Shown are ensemble means except for RCP2.6 where only one simulation exists (a) ocean currents in 109m, 1980-1999

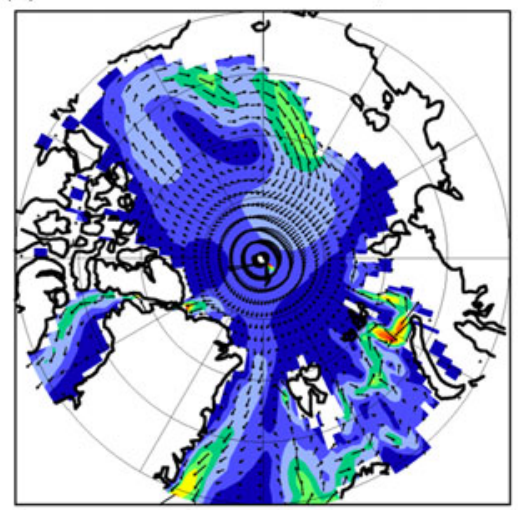

(c) RCP4.5, 2080-2099 $\quad \overline{0.1}$

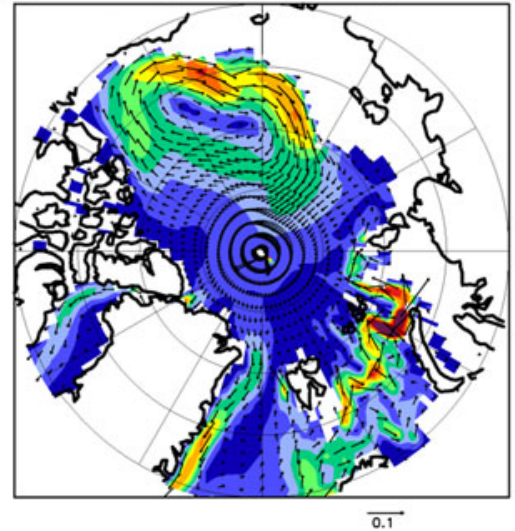

(b) RCP2.6, 2080-2099

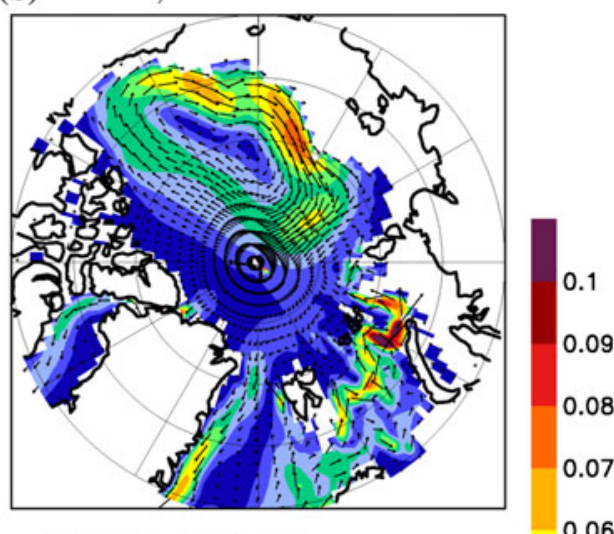

(d) RCP8.5, 2080-2099 $\overline{0.1}$

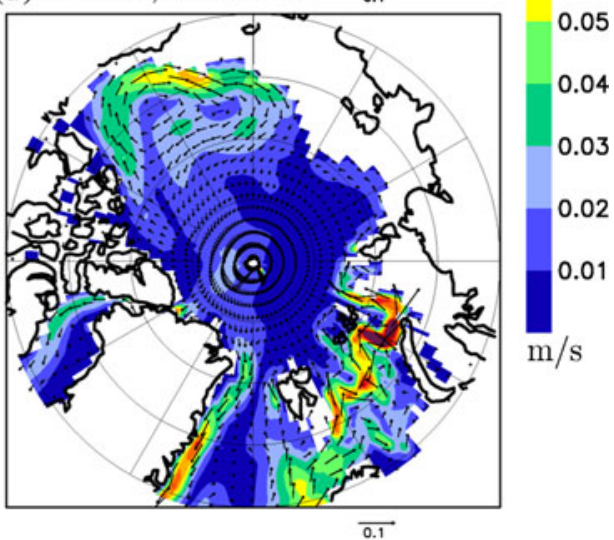

winter cloud fraction in the twentieth century while models with initially high winter cloud fraction, as is the case for EC-Earth, showed very small changes.

In autumn, in contrast to what a majority of the CMIP3 models showed (Vavrus et al. 2009), there is a widespread Arctic reduction in cloudiness of about $10 \%$ for RCP8.5, while for RCP4.5 and 2.6 the mean reductions of 5 and $2 \%$ are concentrated to the Barents Sea region where the sea-ice is reduced. The warming near the surface and at low atmospheric levels dominates over the humidity changes leading to decreased relative humidity at low levels and thereby decreased low level and total cloudiness. However, the total cloud water paths increase fairly evenly all year by 5,10 and $25 \mathrm{~g} / \mathrm{m}^{2}$ in the RCP2.6, 4.5 and 8.5, respectively. The summer and autumn changes are due to increases in LWP over the whole region while IWP decreases over Barents Sea (not shown). For winter and spring the TWP changes are dominated by increased IWP over the remaining sea-ice, moderated by reductions of IWP over the Barents Sea.

The increases in cloud fraction and large increases in TWP in winter and spring over the remaining sea-ice lead to increases in the LW CRF's by $5-10 \mathrm{~W} / \mathrm{m}^{2}$, implying a larger cloud induced warming. The low amounts of liquid water in twentieth century EC-Earth mixed-phase clouds makes the model prone to large changes in cloud emissivity and in the amount of LW emitted to the surface (Willén et al., manuscript in preparation). In summer, despite of the increase in TWP over most of the Arctic, the changes in LW CRF's are close to zero for RCP2.6 and RCP4.5 since the present day cloud emissivities are already close to unity and the changes in surface LW fluxes are smaller (not shown). For RCP8.5 the LW CRF is reduced in summer and autumn due to the reduction in cloud fraction centered over the Barents Sea, the decrease in low-level clouds and increase in high-level clouds reduce the surface LW CRF's but increase the top of atmosphere LW CRF's (not shown).

The EC-Earth SW cloud cooling increases as a result of the increases in LWP in summer and autumn which leads to optically thicker cloud and less SW flux to the surface. The SW CRFs become more negative with the largest decrease in June of $-15,-30$ and $-55 \mathrm{~W} / \mathrm{m}^{2}$, for the RCP 2.6, 4.5 and 8.5 simulations, respectively. The increase in SW cloud radiative cooling is both attributed to the increases in cloud albedo and to the decreases in surface albedo, due to the retreat of the sea-ice (Fig. 4). The cloud albedo changes are responsible for about half of SW CRF reductions seen in Fig. 12h, i.e. EC-Earth clouds reduce the sea-ice albedo feedback.

At the end of the twenty-first century, the total cloud forcing in the EC-Earth simulations is positive from 
(a) temperature, $\mathrm{RCP} 2.6$

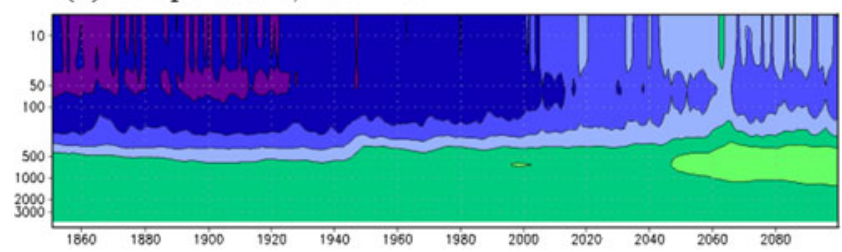

(c) temperature, $\mathrm{RCP} 4.5$

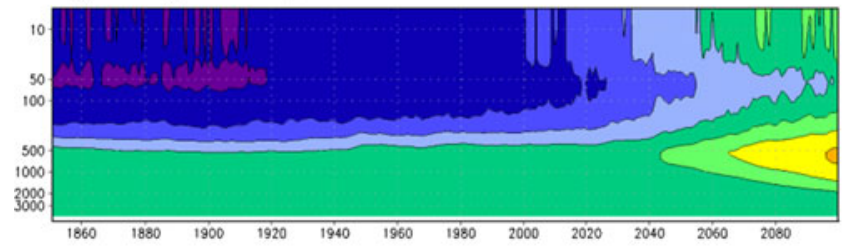

(e) temperature, RCP8.5

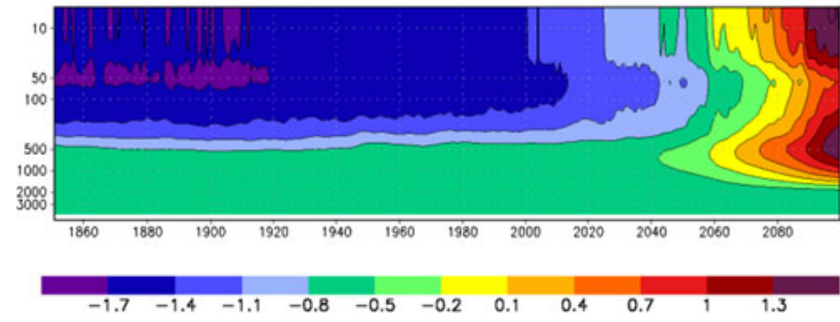

Fig. 16 Vertical ocean temperature $\left(l e f t\right.$, in $\left.{ }^{\circ} \mathrm{C}\right)$ and salinity (right, in psu) distribution in EC-Earth, averaged over the Arctic Ocean (bounded by Fram Strait, Bering Strait, Smith Sound, Lancaster Sound and a line between the southern edge of Svalbard and the Kola

September to May for RCP2.6 and 4.5 and from September to April for RCP8.5 with maximum warming in October of about $50 \mathrm{~W} / \mathrm{m}^{2}$ for all emission scenarios. The cloud forcing is negative from June to August for RCP2.6 and 4.5 and from May to August for RCP8.5, with maximum cooling in July varying from $-30,-50$ to $-70 \mathrm{~W} / \mathrm{m}^{2}$ for RCP2.6, 4.5 and 8.5 scenarios, respectively.

\subsection{Atmospheric meridional energy transport}

The meridional, atmospheric energy transport reaches 4PW in the Northern Hemisphere (NH) mid-latitudes and decreases towards the North Pole. The largest part of the transport is accomplished by the dry-static component, whereas the latent transport stands for a minor contribution. The total transport at a given latitude $\Phi_{O}$ is defined as:

$\int_{\Phi=\Phi_{0}} \int_{0}^{p_{s}}\left(k+c_{p} T+g z+L q\right) v \frac{d p}{g} d x$

where the first three terms in the integral constitute the drystatic transport, and the last term the latent transport. Here $\Phi$ is latitude, $p_{s}$ surface pressure, $\mathrm{k}$ kinetic energy, $c_{p}$ specific heat capacity at constant pressure, $T$ temperature, $g$ gravity, $z$ geopotential height, $L$ latent heat of condensation, (b) salinity, RCP2.6

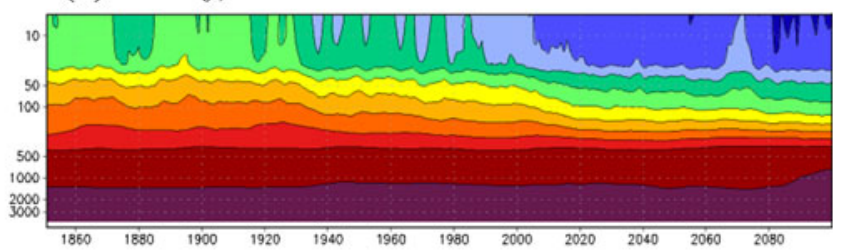

(d) salinity, RCP4.5

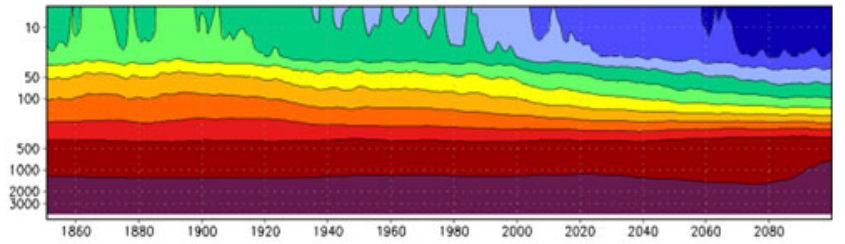

(f) salinity, RCP 8.5

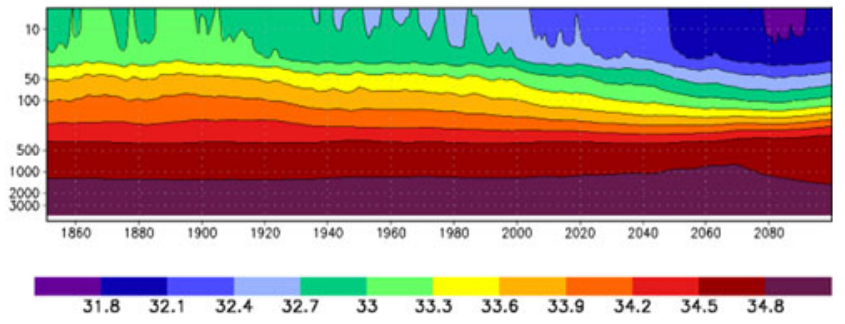

Peninsula at $\left.69^{\circ} \mathrm{N}, 37^{\circ} \mathrm{E}\right)$ in RCP2.6 (a, b), RCP4.5 (c, d), RCP8.5 $(\mathbf{e}, \mathbf{f})$. c-f show ensemble means, $\mathbf{a}$ and $\mathbf{b}$ show the single RCP2.6 simulation with the belonging historical simulation before 2006

$q$ specific humidity, $v$ meridional wind component, $p$ pressure, and $x$ is the zonal coordinate. Estimations based on EC-Earth and ERA-Interim are shown in Figs. 13a and 14a. The transports are estimated with a 6 -h resolution from fields at model hybrid levels. For ERA-Interim a correction is applied to take into account transports associated with erroneous mass fluxes (Trenberth 1997; Graversen 2006; Graversen et al. 2007).

EC-Earth and ERA-Interim are in a fairly good agreement at most high, northern latitudes. In the NH mid-latitudes the disagreement is around $10 \%$ where EC-Earth underestimates the total transport relative to ERA-Interim. The annual EC-Earth transports are also roughly similar to estimates from the NCEP-NCAR reanalysis reported by Trenberth and Stepaniak (2003), but are somewhat larger than the estimation based on rawinsonde measurements over the period 1963-1973 documented by Oort and Peixoto (1983).

The twenty-first century transport changes are shown in Fig. 13b and the split into seasons in Fig. 14b. All seasons except summer show an increase of the latent, but a decrease of the dry-static component north of $60^{\circ} \mathrm{N}$. In summer the total changes are positive but small.

The change in the atmospheric energy transport will likely affect the Arctic climate (Graversen 2006). The 
Fig. 17 a Annual mean total (liquid + solid) freshwater inputs into the Arctic in $\mathrm{m}^{3} / \mathrm{s}$ through Fram Strait (blue), Canadian Archipelago (red), Barents Sea (green) and Bering Strait (maroon) and the sum of all (black) in RCP4.5 (solid) and RCP8.5 (dashed) in EC-Earth. Ensemble means are shown. b Annual mean $\mathrm{P}-\mathrm{E}$ (blue) and river runoff $($ red $)$ in $\mathrm{m}^{3} / \mathrm{s}$ in RCP4.5 (solid) and RCP8.5 (dashed). Ensemble means are shown. c Annual mean liquid (solid) and solid (dashed) fresh water transports in $\mathrm{m}^{3} / \mathrm{s}$ through Fram Strait in ensemble means of twentieth century simulations (black), RCP4.5 (blue) and RCP8.5 (red). d Annual mean Arctic freshwater content in $\mathrm{m}^{3}$ (same area as in Fig. 16) in ensemble means of twentieth century simulations (black), RCP4.5 (blue) and RCP8.5 (red). As reference salinity 34.9 psu has been used (a) total freshwater inflow

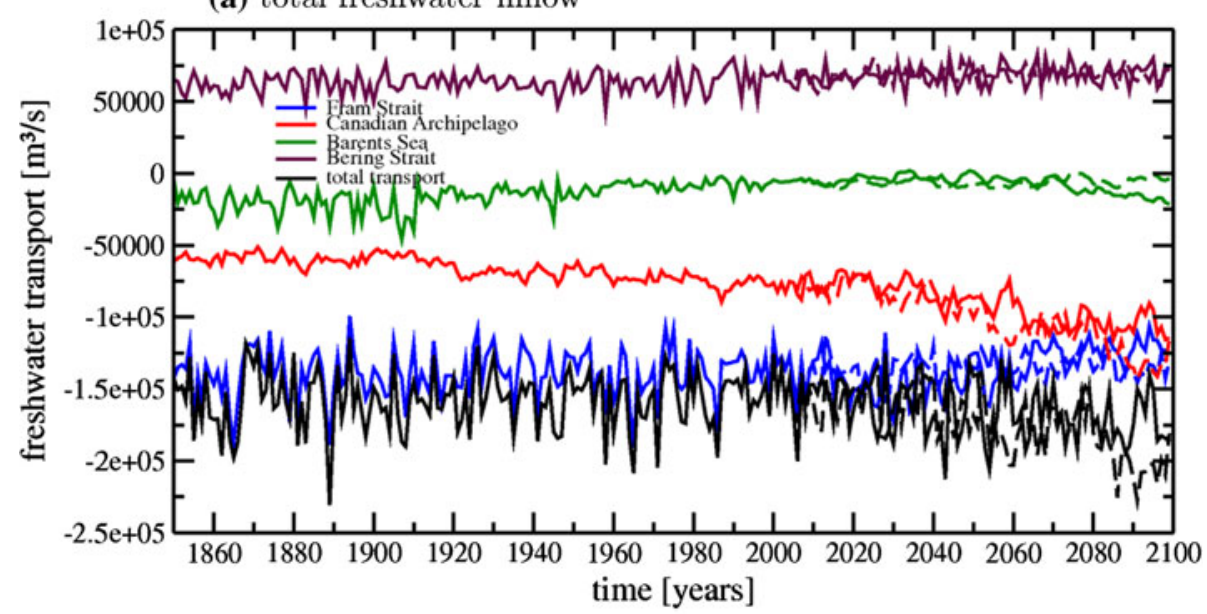

(b) runoff

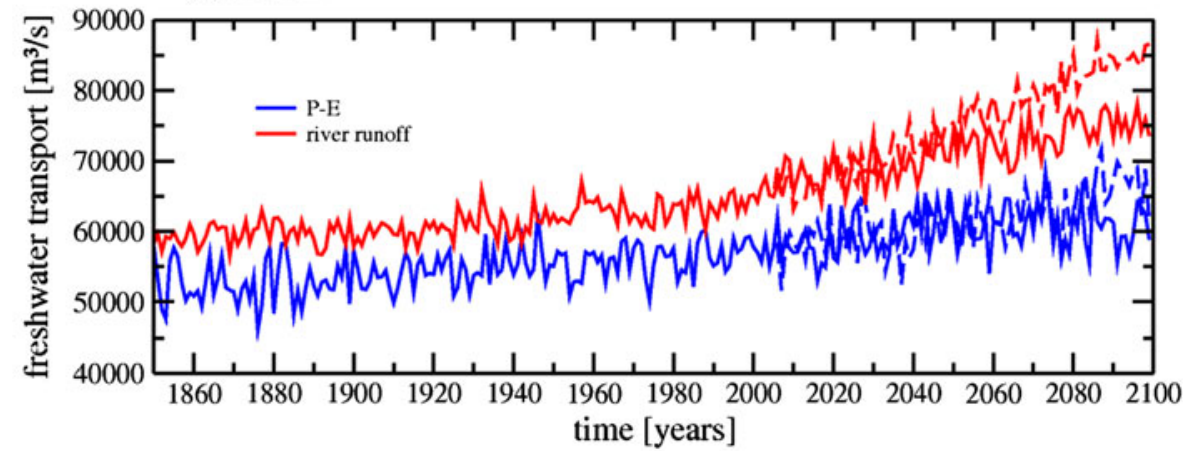

(c) freshwater transport through Fram Strait

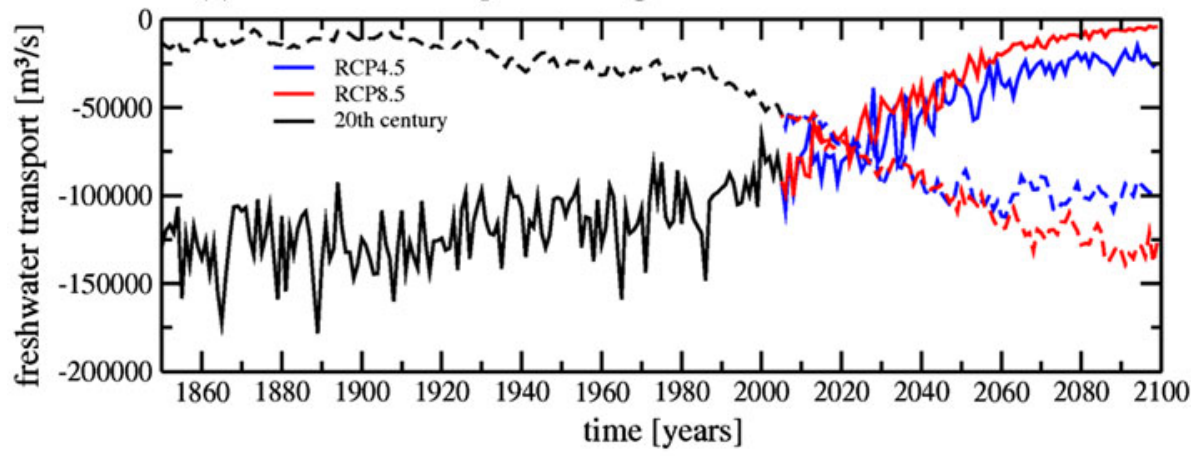

(d) Arctic freshwater content

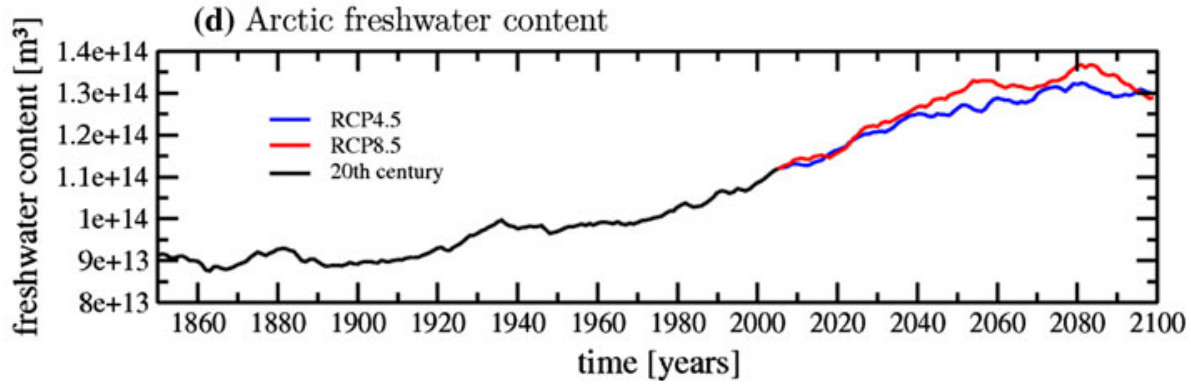

energy-divergence change over the Arctic will directly cause cooling or warming. In addition, changes in the humidity divergence may modify the greenhouse effect over the Arctic, due to changes in both humidity and cloudiness, hereby altering the surface-energy budget. Hence, the reduction at the Arctic boundary of the atmospheric meridional energy transport over the twenty-first century in the three darker seasons, as simulated by 
Fig. 18 a 10-year running means of ocean heat transport across $70^{\circ} \mathrm{N}$ in W in EC-Earth in ensemble means of twentieth century simulations, RCP4.5, RCP8.5 and in the single RCP2.6 simulation. b Annual mean heat transports in $\mathrm{W}$ through Fram Strait (blue), Canadian Archipelago (red), Barents Sea (green) and Bering Strait (maroon) and the sum of all (black) in RCP4.5 (solid) and RCP8.5 (dashed). Ensemble means are shown. c Annual mean Arctic Ocean heat content anomalies in $\mathbf{J}$ in ensemble means of twentieth century simulations (black), RCP4.5 (blue) and RCP8.5 (red) and in one RCP2.6 simulation (green). The single twentieth century simulation belonging to the single RCP2.6 simulation is also shown in green. Reference period is $1950-1999$ (a) ocean heat transport across $70 \mathrm{~N}$

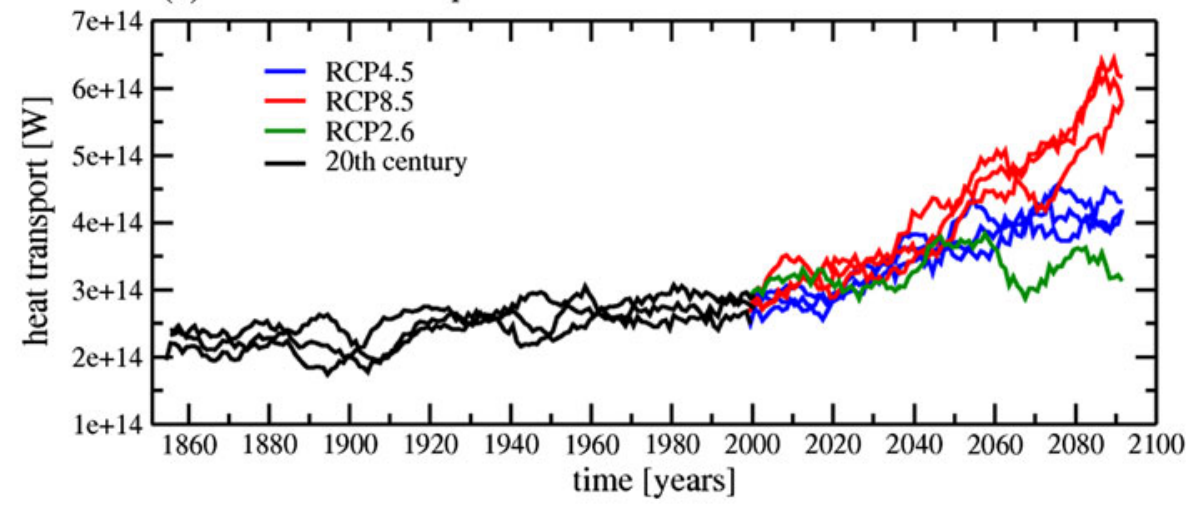

(b) heat transport through Arctic straits
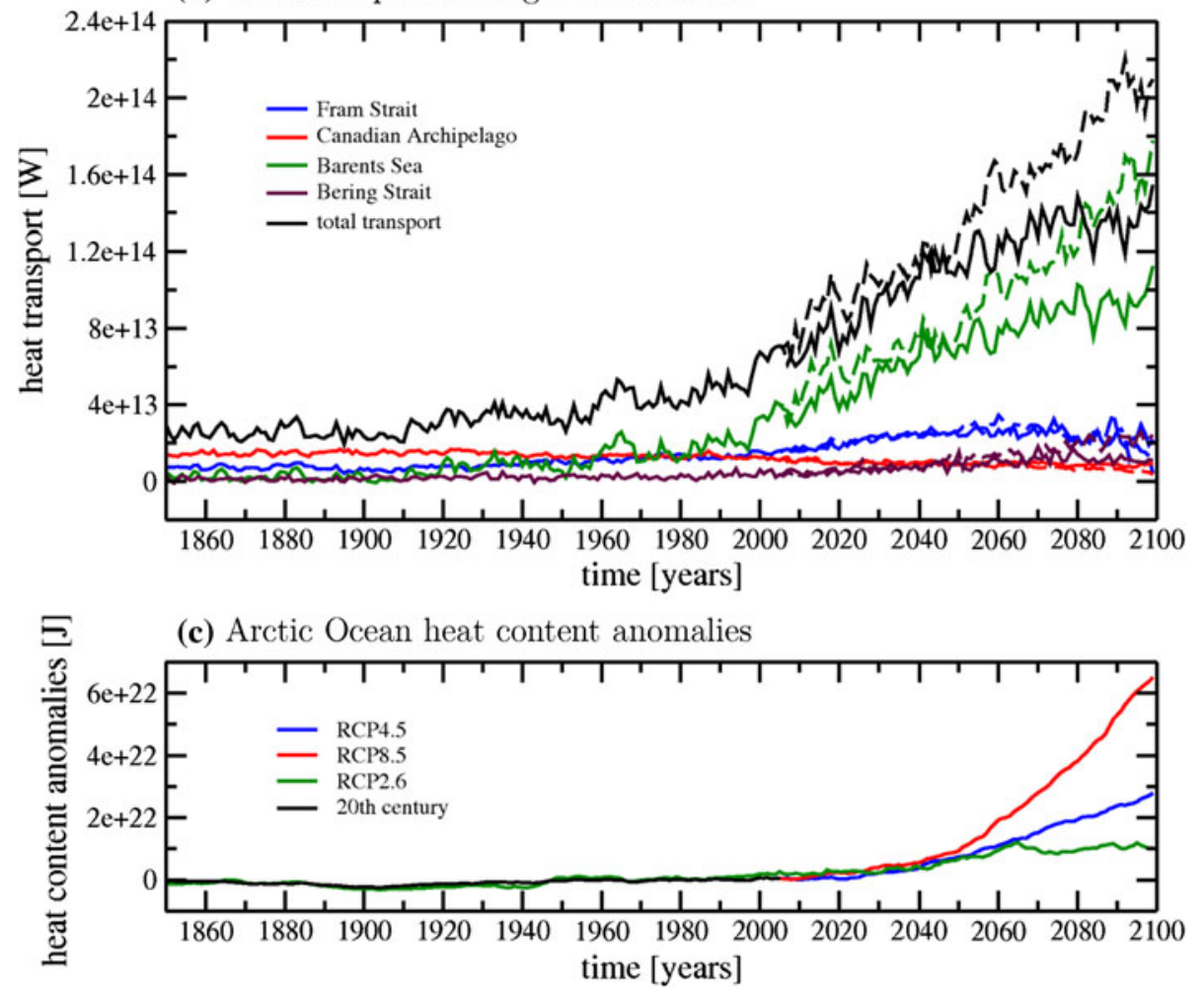

EC-Earth, will likely in itself reduce the Arctic temperature amplification. However, at the same time, the increase of the latent component may enhance the greenhouse effect and contribute to an enhancement of the amplification. Also note that zonal variations of the transport change and non-linear feedbacks may be important: If the transport increases over areas with thin sea ice, the warming effect may be larger than the cooling effect from a corresponding reduction of the transport elsewhere. A warm anomaly over thin sea ice may melt the ice and expose the ocean surface whereby feedbacks such as that of surface albedo are invoked. In contrast, a cold anomaly over an ice area where the ice is normally retained by the end of the summer would reduce the ice melt but cause little albedo change.

\subsection{Arctic Ocean circulation}

The Arctic ocean circulation in layers near the surface is characterized by a pronounced Beaufort Gyre, transpolar currents from the Siberian coast towards Fram Strait and southerly flows through Fram Strait as well as inflowing waters through the Barents Sea opening and further along the Siberian coast. Limited observations make an evaluation difficult. However, results from e.g. Morison et al. (2012) indicate a similar circulation pattern of the real Arctic Ocean mixed layer but the Beaufort Gyre seems to be slightly too extended in our model. Figure 15 compares the ensemble mean currents below the mixed layer in the Arctic at $109 \mathrm{~m}$ for the end of the twentieth century and at 
the end of the twenty-first century in RCPs 2.6, 4.5 and 8.5. In RCP2.6 and RCP4.5, the currents are generally strengthened compared to the twentieth century but the patterns stay similar. The reduction in sea ice leads to increased wind stress on the ocean and thus to enhanced currents. A comparison to the SLP changes (Fig. 10c-e) indicates that enhanced south-westerly wind stress is responsible for enhanced inflow into the Barents Sea. In RCP8.5, the inflow through the Barents Sea is further strengthened due to additional increase in the southwesterlies over the Nordic Seas. Also the circulation pattern in the Arctic Basin changes substantially. The size of the Beaufort Gyre is reduced and is displaced towards Chukchi Sea. This leads to strongly reduced velocities in the transpolar drift. Anomalously on-shore winds at the Siberian coast (Fig. 10e) are responsible for at least parts of the simulated changes.

\subsection{Arctic Ocean temperature and salinity}

The twentieth century Arctic Ocean is characterized by a cold and fresh upper layer and warmer and more saline water masses in deeper layers (Fig. 16). Compared to observations (World Ocean Atlas 2009: Antonov et al. 2010 and Locarnini et al. 2010), the upper layer in EC-Earth is slightly too cold and too saline. Furthermore, the observed warm layer at around $500 \mathrm{~m}$, which is caused by the warm and saline inflowing Atlantic water, is not sufficiently pronounced and does not appear at all in the twentieth century. The CCSM4 model (Jahn et al. 2012) show similar to our model a too saline upper layer and no pronounced intermediate Atlantic water masses. The inflowing warm Atlantic water masses are rapidly mixed into larger depth after entering the Arctic Ocean in EC-Earth. Within the twenty-first century, a more pronounced warm water layer is formed. In RCP2.6, the cold surface layer persists during the entire twenty-first century while in RCP8.5 the surface layer is warmed most, by up to $3 \mathrm{~K}$.

Salinity in the twenty-first century decreases by up to $-1.5 \mathrm{psu}$ in the upper $100 \mathrm{~m}$. This agrees well to model results by Koenigk et al. (2007) who found a maximum decrease of -1.8 psu near the surface in the A1B scenario. The salinity differences between the RCPs in our simulations are not as pronounced as for temperature but we see a clear tendency to more freshening in the higher emission scenarios.

\subsection{Arctic Ocean freshwater budget}

The Arctic Ocean freshwater budget has been calculated with a reference salinity of 34.9 psu, taken from the twentieth century inflowing Atlantic water in our model.
In the twentieth century, the simulated freshwater transports (Fig. 17a) agree relatively well to observational based estimates (Serreze et al. 2006). However, the liquid freshwater exports through Fram Strait and the Canadian Archipelago are underestimated by about $30 \%$. For Fram Strait, this is partly compensated by too large sea ice export. The river runoff into the Arctic is too small and might explain the high surface salinity and low liquid freshwater export biases. Similar to EC-Earth, the CCSM4model is overestimating Fram Strait ice export and underestimating the liquid freshwater export (Jahn et al. 2012). In contrast to EC-Earth, CCSM4 is overestimating the river runoff but shows a more realistic export through the Canadian Archipelago.

The change in the total freshwater transport (solid + liquid) out of the Arctic is relatively small despite a strong increase in the freshwater input by $\mathrm{P}-\mathrm{E}$ and river runoff in the twenty-first century. After 2030, the total export is slightly increased and this trend is accelerated in RCP8.5 at the end of the twenty-first century. Investigating the individual straits, a strong increase of the total freshwater export through the Canadian Archipelago is evident, while the total exports through the Fram Strait and through the Barents Sea are slightly reduced. The transport through Bering Strait shows a slight increase. After 2060, we see accelerated changes in RCP8.5 compared to RCP4.5. The freshwater transports are dominated by the liquid transport except for Fram Strait (Fig. 17c) where the ice export dominates. In the twenty-first century, ice export is strongly reduced while the liquid export increases.

The additional freshwater input into the Arctic exceeds the increase in the exports in the twenty-first century simulations. As a consequence, the Arctic Ocean fresh water content grows (Fig. 17d). This growth is similar in all RCPs since the larger freshwater input in the higher RCPs is to a large degree compensated by larger exports.

\subsection{Ocean heat transport}

The ocean heat transport into the Arctic is shown in Fig. 18. We calculated the heat transport across $70^{\circ} \mathrm{N}$ as residuum of the integrated surface heat fluxes and the change in ocean heat content north of $70^{\circ} \mathrm{N}$ (Fig. 18a). The heat transports through the Arctic openings (Fig. 18b) have been estimated by calculating the product of velocity perpendicular to the opening, the difference of ocean temperature to a reference temperature, the density of the water mass and the specific heat capacity of the water. Similar to most other studies, we use $0{ }^{\circ} \mathrm{C}$ as the reference temperature. We tested the robustness of the results against changes in the reference temperature and found that the mean heat fluxes are different but that the twenty-first century changes are insensitive. 
The twentieth century heat transport across $70^{\circ} \mathrm{N}$ sums up to $0.27 \mathrm{PW}$. This is in good agreement to observational based estimate by Oliver and Heywood (2003) who found a transport of $0.2 \pm 0.08 \mathrm{PW}$ across a section at approximately $70^{\circ} \mathrm{N}$ between Greenland and Norway. It also compares well to model results by Jungclaus and Koenigk (2010), who found a transport of $0.28 \mathrm{PW}$ across $70^{\circ} \mathrm{N}$. In the twenty-first century, the heat transport is strongly growing and reaches $0.32,0.41$ and $0.6 \mathrm{PW}$ in RCP2.6, RCP4.5 and RCP8.5, respectively.

The total heat transport into the Arctic Ocean reaches 50TW; 20TW are transported through Barents Sea (across a line connecting Svalbard with the Kola Peninsula at $69^{\circ} \mathrm{N}, 37^{\circ} \mathrm{E}$ ) and about $15 \mathrm{TW}$ each through Fram Strait and Canadian Archipelago. Measurements indicate heat fluxes of about 50TW through the Barents Sea Opening (Skagseth et al. 2008) and 30-40TW through Fram Strait (Schauer et al. 2008). Obviously, EC-Earth underestimates the heat flux through Fram Strait. The underestimation of heat and volume flux through Fram Strait into the Arctic is a common problem in global coupled models, probably due to insufficient resolution and is also seen in the CCSM4-model (Jahn et al. 2012). The Barents Sea section used by Skagseth et al. (2008) was further to the south and west than our section and loss of heat to the atmosphere within the Barents Sea can explain at least parts of the differences. At the end of the twenty-first century, the heat flux through the Barents Sea is strongly enhanced and the ensemble averages reach 100TW and 160TW in RCP4.5 and RCP8.5, respectively. The single RCP2.6 member reaches about 70TW at 2050 but decreases somewhat thereafter (not shown). The strong increase of heat transport in the Barents Sea is due both to the temperature increase of the transported water masses and increased northward volume transport. The volume transport through Barents Sea is enhanced from $2.7 \mathrm{~Sv}$ at the end of the twentieth century to $3.7 \mathrm{~Sv}$ and $4.2 \mathrm{~Sv}$ in RCP4.5 and RCP8.5, respectively. The increase is probably mainly caused by strengthened south-westerly winds in the Nordic Seas (compare Fig. 10).

The heat transport through the Barents Sea opening governs sea ice variations in the Barents and Kara Sea on decadal scale time periods. The correlation is -0.75 $(-0.95)$ between 10-year running means of heat transport and the detrended (including trend) Barents Sea/Kara Sea ice area time series. We hypothesize that the increasing ocean heat transport strongly contributes to the reduced sea ice cover in the Barents and Kara Sea region and thus also contributes to the Arctic temperature amplification.

The Arctic Ocean heat content is strongly growing in the twenty-first century (Fig. 18c). However, the integrated heat flux anomaly into the Arctic in the twenty-first century is about twice the heat content anomaly. This means that about $50 \%$ of the inflowing ocean heat anomaly in the twenty-first century is either used to melt sea ice or passed to the atmosphere.

\section{Summary and conclusions}

This study analysed the mean Arctic climate change in an ensemble of different future climate scenario simulations based on the CMIP5 emission scenarios with the global coupled climate model EC-Earth2.3.

We also evaluated EC-Earth for the twentieth century Arctic climate. Generally, EC-Earth simulates a reasonable Arctic climate. However, the Arctic is about $2 \mathrm{~K}$ too cold and sea ice thickness and extent are overestimated compared to observations and reanalyses.

In the twenty-first century, most of the observed climate changes of the last decades continue.

The different emission scenarios result in similar Arctic climate changes until about the middle of the twentyfirst century. Thereafter, the differences in atmospheric $\mathrm{CO}_{2}$ concentration and Arctic climate change are rapidly increasing.

In the low emission scenario RCP2.6, the changes are mainly concentrated to the Barents Sea region due to the strongest sea ice reduction there. After 2060, the RCP2.6 scenario simulation even shows some recovery in a number of variables. In the high emission scenario RCP8.5, we see a dramatically changed Arctic climate at the end of the century. The ocean is totally ice free and substantially warmed during summer. The Arctic atmosphere is much less stable during winter-time, which strongly modifies vertical processes.

All three RCP8.5 ensemble members show an abrupt summer sea ice reduction around 2060 and a nearly ice free Arctic Ocean during late summer thereafter. This might indicate that a tipping point is reached at around 2060. Taking the overestimation of sea ice extent and thickness in EC-Earth into account, our results indicate likelihood for almost total summer sea ice loss in about 30 years from now in RCP8.5.

Our scenario simulations show a strong amplified Arctic warming, which is mostly confined near the surface and declines with increasing altitude. The warming is largest in autumn and winter and most pronounced in the Barents Sea. Here, we also find the largest increases in latent and sensible heat fluxes and a reduction in the cloud fraction. However, while low-level clouds are largely reduced, midand high-level clouds show a slight increase. The cloud changes contribute to Arctic warming during winter and reduce the warming at the surface in summer in our scenario simulations. 
The SLP is generally reduced in the Arctic. Simultaneously, SLP increases over the north-eastern North Atlantic and Western Europe and the south-west winds over the Nordic Seas are strengthened. This contributes to enhanced ocean volume transports into the Arctic, which leads, together with the warming of the ocean, to strongly enhanced ocean heat transports into the Arctic. Particularly, the heat flux through the Barents Sea Opening grows and contributes to enhanced sea ice melt and warming in the Barents and Kara Seas region.

The total atmospheric energy flux to the north is substantially reduced north of about $55^{\circ} \mathrm{N}$ and seems to dampen the Arctic warming in EC-Earth. On the other hand, the transport of latent heat to the north is increased, which may lead to an enhancement of the greenhouse gas effect over the Arctic.

The upper ocean currents in the Arctic Ocean are strengthened in RCP2.6 and RCP4.5 and the entire circulation pattern is substantially changed at the end of the twenty-first century in RCP8.5. The ocean stratification is strongly modified by warming and freshening of the upper layers and by a more pronounced intermediate water.

Enhanced precipitation and river runoff increase the freshwater input into the Arctic Ocean. However, most of the additional freshwater is stored in the Arctic Ocean. The total freshwater export out of the Arctic is only slightly changing and probably does not play a dominant role in reducing North Atlantic deep water convection in EC-Earth.

Although all ensemble members of the same emission scenario generally show the same trends and similar change patterns, we found substantial differences between the ensemble members on decadal time scales or even longer. This implies uncertainties in the climate change signal due to the natural variability. An ensemble of three members as used in this study is not sufficient to totally capture the entire natural variability. However, we find that for all variables except for SLP the change signal until the end of the twenty-first century is substantially larger than the ensemble spread and the uncertainties due to the emission scenario are much larger than the uncertainties due to natural variability.

Acknowledgments This study has been made possible by support of the Rossby Centre at the Swedish Meteorological and Hydrological Institute (SMHI) together with the Swedish Research Council Formas financed project ADSIMNOR. We thank Ulf Hansson and Laurent Brodeau for performing the model simulations.

Open Access This article is distributed under the terms of the Creative Commons Attribution License which permits any use, distribution, and reproduction in any medium, provided the original author(s) and the source are credited.

\section{References}

ACIA (2005) Arctic climate impact assessment. Cambridge University Press, Cambridge, p 1042

Alexander M, Bhatt U, Walsh J, Timlin M, Miller J, Scott J (2004) The atmospheric response to realistic Arctic sea ice anomalies in an AGCM during winter. J Clim 17:890-905

Antonov JI, Seidov D, Boyer TP, Locarnini RA, Mishonov AV, Garcia HE, Baranova OK, Zweng MM, Johnson DR (2010) World Ocean Atlas 2009, Volume 2: Salinity. In: Levitus S (ed) NOAA Atlas NESDIS 69, US Government Printing Office, Washington, $184 \mathrm{pp}$

Balsamo G, Viterbo P, Beljaars A, van den Hurk B, Betts A, Scipal K (2009) A revised hydrology for the ECMWF model: verification from field site to terestrial water storage and impact in the Integrated Forecast System. J Hydrometerol 10:623-643

Bechtold P, Köhler M, Jung T, Leutbecher M, Rodwell M, Vitart F, Balsamo G (2008) Advances in predicting atmospheric variability with the ECMWF model, 2008: from synoptic to decadal time-scales. Q J Roy Meteorol Soc 134:1337-1351

Belchansky GI, Douglas DC, Platonov NG (2008) Fluctuating Arctic sea ice thickness changes estimated by an in situ learned and empirically forced neural network model. J Clim 21:716-729. doi:10.1175/2007JCLI1787.1

Belkin I, Levitus S, Antonov J, Malmberg SA (1998) "Great salinity anomalies" in the North Atlantic. Prog Oceanogr 41:1-68

Bintanja R, Graversen RG, Hazeleger W (2011) Arctic winter warming amplified by the thermal inversion and consequent low infrared cooling to space. Nat Geosci Lett. doi:10.1038/NGEO1285

Bitz C, Fyfe J, Flato G (2002) Sea ice response to wind forcing from AMIP models. J Clim 15:522-536

Bouillon S, Morales Maqueda MA, Legat V, Fichefet T (2009) An elastic-viscous-plastic sea ice model formulated on Arakawa B and C grids. Ocean Model 27(3-4):174-184. doi:10.1016/j. ocemod.2009.01.004

Cavalieri D, Parkinson C, Gloersen P, Zwally HJ (1996, updated yearly) Sea ice concentrations from Nimbus-7 SMMR and DMSP SSM/I-SSMIS passive microwave data, 1980-1999. National Snow and Ice Data Center, Boulder, Colorado, USA. Digital media

Chapman WL, Walsh JE (2007) Simulations of Arctic temperature and pressure by global coupled models. J Clim 20:609-632. doi: 10.1175/JCLI4026.1

Comiso JC, Parkinson C, Gersten R, Stock L (2008) Accelerated decline in the Arctic sea ice cover. Geophys Res Lett 35(L01703). doi:10.1029/2007GL031972

De Boer G, Chapman W, Kay JE, Medeiros B, Shupe MD, Vavrus S, Walsh J (2012) A characterization of the present-day Arctic atmosphere in CCSM4. J Clim 25:2676-2695. doi:10.1175/ JCLI-D-11-00228.1

Dee DP, Uppala SM, Simmons AJ, Berrisford P, Poli P, Kobayashi S, Andrae U, Balmaseda MA, Balsamo G, Bauer P, Bechtold P, Beljaars ACM, van de Berg L, Bidlot J, Bormann N, Delsol C, Dragani R, Fuentes M, Geer AJ, Haimberger L, Healy SB, Hersbach H, Holm EV, Isaksen L, Kållberg P, Köhler M, Matricardi M, McNally AP, Monge-Sanz BM, Morcrette JJ, Park BK, Peubey C, de Rosnay P, Tavolato C, Thepaut JN, Vitart F (2011) The ERA-Interim reanalysis: configuration and performance of the data assimilation system. Q J R Meteorol Soc 137:553-597. doi:10.1002/qj.828

Deser C, Tomas R, Alexander M, Lawrence D (2010) The seasonal atmospheric response to projected Arctic sea ice loss in the late twenty-first century. J Clim 23:333-351. doi:10.1175/2009JCLI 3053.1 
Deser C, Philips A, Bourdette V, Teng H (2012) Uncertainty in climate change projections: the role of internal variability. Clim Dyn 38:527-546. doi: 10.1007/s00382-010-0977-x

DeWeaver E, Bitz CM (2006) Atmospheric circulation and its effect on Arctic sea ice in CCSM3 simulations at medium and high resolution. J Clim 19:2415-2436

Dickson R, Meincke J, Malmberg SA (1988) The "great salinity anomaly" in the northern North Atlantic, 1968-1982. Prog Oceanogr 20:103-151

Dutra E, Balsamo G, Viterbo P, Miranda PMA, Beljaars A, Schär C, Elder K (2010) An improved snow scheme for the ECMWF land surface model: description and offline validation. J Hydrometeorol 11:899-916. doi:10.1175/2010JHMI249.1

Fichefet T, Morales Maqueda MA (1997) Sensitivity of a global sea ice model to the treatment of ice thermodynamics and dynamics. J Geophys Res 102(C6):609-612. doi:10.1029/97JC00480

Graversen RG (2006) Do Changes in the mid-latitude circulation have any impact on the Arctic surface air temperature trend? J Clim 19:5422-5438

Graversen RG, Wang M (2009) Polar amplification in a coupled climate model with locked albedo. Clim Dyn 33:629-643. doi: 10.1007/s00382-009-0535-6

Graversen RG, Källén E, Tjernström M, Körnich H (2007) Atmospheric mass-transport inconsistencies in the ERA-40 reanalysis. Q J R Meteorol Soc 133:673-680

Graversen RG, Mauritsen T, Tjernström T, Källén E, Svensson G (2008) Vertical structure of recent Arctic warming. Nature 541. doi:10.1038/nature06502

Graversen RG, Mauritsen T, Drijfhout S, Tjernström M, Mårtensson S (2011) Warm winds from the Pacific caused extensive Arctic sea-ice melt in summer 2007. Clim Dyn 36(11-12):2103-2112. doi:10.1007/s00382-010-0809-z

Haak H, Jungclaus J, Mikolajewicz U, Latif M (2003) Formation and propagation of great salinity anomalies. Geophys Res Lett 30(9): $26 / 1-26 / 4$

Häkkinen S (1999) A simulation of thermohaline effects of a great salinity anomaly. J Clim 6:1781-1795

Hazeleger W, Severijns C, Semmler T, Stefanescu S, Yang S, Wang X, Wyser K, Baldasano JM, Bintanja R, Bougeault P, Caballero R, Dutra E, Ekman AML, Christensen JH, van den Hurk B, Jimenez P, Jones C, Kållberg P, Koenigk T, MacGrath R, Miranda P, van Noije T, Schmith T, Selten F, Storelvmo T, Sterl A, Tapamo H, Vancoppenolle M, Viterbo P, Willén U (2010) EC-Earth: a seamless earth system prediction approach in action. Bull Am Meteorol Soc 91:1357-1363. doi:10.1175/2010BAMS 2877.1

Hazeleger W, Wang X, Severijns C, Stefanescu S, Bintanja R, Sterl A, Wyser K, Semmler T, Yang S, van den Hurk B, van Noije T, van der Linden E, van der Wiel K (2012) EC-Earth V2: description and validation of a new seamless earth system prediction model. Clim Dyn. doi:10.1007/s00382-011-1228-5

Holland MM, Bitz CM (2003) Polar amplification of climate change in coupled models. Clim Dyn 21:221-232

Holland MM, Bitz CM, Eby M, Weaver AJ (2001) The role of iceocean interactions in the variability of the North Atlantic thermohaline circulation. J Clim 14:656-675

Holland MM, Bitz CM, Tremblay B (2006) Future abrupt reductions in the summer Arctic sea ice. Geophys Res Lett 33(L23503). doi: 10.1029/2006GL028024

IPCC (2007) Climate change 2007: the physical science basis. Contribution of working group i to the fourth assessment report of the intergovernmental panel on climate change. In: Solomon S, Qin D, Manning M, Chen Z, Marquis M, Averyt KB, Tignor M, Miller HL (eds) Cambridge University Press, Cambridge

Jahn A, Sterling K, Holland MM, Kay JE, Maslanik JA, Bitz CM, Bailey DA, Stroeve J, Hunke EC, Lipscomb WH, Pollak DA
(2012) Late-twentieth-century simulation of Arctic sea ice and ocean properties in the CCSM4. J Clim 25:1431-1452. doi: 10.1175/JCLI-D-11-00201.1

Jungclaus JH, Haak H, Latif M, Mikolajewicz U (2005) Arctic-North Atlantic interactions and multidecadal variability of the meridional overturning circulation. J Clim 18(19):4016-4034

Jungclaus JH, Koenigk T (2010) Low-frequency variability of the Arctic climate: the role of oceanic and atmospheric heat transport variations. Clim Dyn 34(2-3):265-279. doi:10.1007/ s00382-009-0569-9

Kalnay E, Kanamitsu M, Kistler R, Collins W, Deaven D, Gandin L, Iredell M, Saha S, White G, Woollen J, Zhu Y, Chelliah M, Ebisuzaki W, Higgins W, Janowiak J, Mo KC, Ropelewski C, Wang J, Leetmaa A, Reynolds R, Jenne R, Joseph D (1996) The NCEP/NCAR 40-year reanalysis project. Bull Am Meteorol Soc 77:437-471

Karlsson J, Svensson G (2011) The simulation of Arctic clouds and their influence on the winter surface temperature in present-day climate in the CMIP3 multi-model dataset. Clim Dyn 36: 623-635

Kay JE, L'Ecuyer T, Gettleman A, Stephens G, O'Dell C (2008) The contribution of cloud and radiation anomalies to the 2007 Arctic sea ice extent minimum. Geophy Res Lett 35(L08503). doi: 10.1029/2008GL033451

Key J (2002) The cloud and surface parameter retrieval (CASPR) system for polar AVHRR user's guide. Technical report, Cooperative Institute for Meteorological Satellite Studies, University of Wisconsin, Wisconsin, $61 \mathrm{pp}$. http://stratus.ssec.wisc. edu/caspr/documentation.html

Koenigk T, Mikolajewicz U, Haak H, Jungclaus J (2006) Variability of Fram Strait sea ice export: causes, impacts and feedbacks in a coupled climate model. Clim Dyn 26:17-34. doi:10.1007/ s00382-005-0060-1

Koenigk T, Mikolajewicz U, Haak H, Jungclaus J (2007) Arctic freshwater export in the 20th and 21st Century. J Geophys Res 112. doi:10.1029/2006JG000274

Koenigk T, Mikolajewicz U, Jungclaus J, Kroll A (2009) Sea ice in the Barents Sea: seasonal to interannual variability and climate feedbacks in a global coupled model. Clim Dyn 32:1119-1138. doi:10.1007/s00382-008-0450-2

Koenigk T, Döscher R, Nikulin G (2011) Arctic future scenario experiments with a coupled regional climate model. Tellus 63A(1):69-86. doi:10.1111/j.1600-0870.2010.00474.x

Liu Y, Key JR, Wang X (2008) The influence of changes in cloud cover on recent surface temperature trends in the Arctic. J Clim 21:705-715

Locarnini RA, Mishonov AV, Antonov JI, Boyer TP, Garcia HE, Baranova OK, Zweng MM, Johnson DR (2010) World Ocean Atlas 2009, Volume 1: temperature. In: Levitus S (ed) NOAA Atlas NESDIS 69, U.S. Government Printing Office, Washington, $184 \mathrm{p}$

Madec G (2008) "NEMO ocean engine". Note du Pole de modélisation, Institut Pierre-Simon Laplace (IPSL), France, No 27 ISSN no $1288-1619$

Magnusdottir G, Deser C, Saravanan R (2004) The effects of North Atlantic SST and sea ice anomalies on the winter circulation in CCM3. Part 1: main features and storm track characteristics of the response. J Clim 17:857-876

Medeiros B, Deser C, Tomas RA, Kay JE (2011) Arctic inversion strength in climate models. J Clim 24:4733-4740. doi:http://dx. doi.org/10.1175/2011JCLI3968.1

Morison J, Kwok R, Peralta-Ferriz C, Alkire M, Rigor I, Andersen R, Steele M (2012) Changing Arctic Ocean freshwater pathways. Nature 481:66-70. doi:10.1038/nature10705

Moss RH, Edmonds JA, Hibbard KA, Manning MR, Rose SK, van Vuuren DP, Carter TR, Emori S, Kainuma M, Kram T, Meehl 
GA, Mitchell JFB, Nakicenovic N, Riahi K, Smith SJ, Stouffer RJ, Thomson AM, Weyant JP, Wilbanks TJ (2010) The next generation of scenarios for climate change research and assessment. Nature 463:747-756. doi:10.1038/nature08823

Oliver KE, Heywood KJ (2003) Heat and freshwater fluxes through the Nordic Seas. J Phys Oceanogr 33:1009-1026

Oort AH, Peixoto JP (1983) Global angular momentum and energy balance requirements from observations. Adv Geophys 25: $355-490$

Overland JE, Wang M (2010) Large-scale atmospheric circulation changes are associated with the recent loss of Arctic sea ice. Tellus 62. doi:10.1111/j.1600-0870.2009.00421.x

Richter-Menge J, Jeffries M (2011) The Arctic, in "State of the Climate in 2010". Bull Am Meteorol Soc 92(6):S143-S160

Rothrock DA, Zhang J, Yu Y (2003) The Arctic ice thickness anomaly of the $1990 \mathrm{~s}$ : a consistent view from observations and models. J Geophys Res 108(C3):3083. doi:10.1029/2001JC 001208

Schauer U, Beszynnska-Möller A, Walczowski W, Fahrbach E, Piechura J, Hansen E (2008) Variation of measured heat flow through the Fram Strait between 1997 and 2006. In: Dickson B, Meincke J, Rhines $\mathrm{P}$ (eds) Arctic-subarctic ocean fluxes: defining the role of Nordic Seas in climate, chap 3. Springer, Berlin

Screen JA, Simmonds I (2010a) Increasing fall-winter energy loss from the Arctic Ocean and its role in Arctic temperature amplification. Geophys Res Lett 37(L16707). doi:10.1029/2010 GL044136

Screen JA, Simmonds I (2010b) The central role of diminishing sea ice in recent Arctic temperature amplification. Nature 464. doi: 10.1038/nature09051

Serreze MC, Hurst CM (2000) Representation of mean Arctic precipitation from NCEP-NCAR and ERA reanalyses. J Clim 13:182-201

Serreze MC, Barrett AP, Slater AG, Woodgate RA, Aagaard K, Lammers RB, Steele M, Moritz R, Meredith M, Lee CM (2006) The large-scale freshwater cycle of the Arctic. J Geophys Res 111(C11010). doi:10.1029/2005JC003424

Serreze MC, Barrett AP, Stroeve JC, Kindig DN, Holland MM (2009) The emergence of surface-based Arctic amplification. Cryosphere 3:11-19

Skagseth Ǿ, Furevik T, Ingvaldsen R, Loeng H, Mork KA, Orvik KA, Ozhigin V (2008) Volume and heat transports to the Arctic Ocean via the Norwegian and Barents Seas. In: Dickson B, Meincke J, Rhines P (eds) Arctic-Subarctic ocean fluxes: defining the role of Nordic Seas in climate, chap 2. Springer, Berlin

Sorteberg A, Furevik T, Drange H, Kvamstø NG (2005) Effects of simulated natural variability on Arctic temperature projections. Geophys Res Lett 32(L18708). doi:10.1029/2005GL023404

Sorteberg A, Kattsov V, Walsh JE, Pavlova T (2007) The Arctic surface energy budget as simulated with the IPCC AR4 AOGCMs. Clim Dyn 29:131-156

Steele M, Zhang J, Ermold W (2010) Mechanisms of summertime upper Arctic Ocean warming and the effect on sea ice melt. J Geophys Res 115(C11004). doi:10.1029/2009JC005849

Sterl A, Bintanja R, Brodeau L, Gleeson E, Koenigk T, Schmith T, Semmler T, Severijns C, Wyser K, Yang S (2012) A look at the ocean in the EC-Earth climate model. Clim Dyn. doi: 10.1007/s00382-011-1239-2

Stroeve J, Holland M, Meier W, Scambos T, Serreze M (2007) Arctic sea ice decline: faster than forecast. Geophys Res Lett 34(L09501). doi:10.1029/2007GL029703

Tjernström M, Birch CE, Brooks IM, Shupe MD, Persson POG, Sedlar J, Mauritsen T, Leck C, Paatero J, Szczodrak M, Wheeler CE (2012) Meteorological conditions in the central Arctic summer during the Arctic summer cloud ocean study (ASCOS). Atmos Chem Phys 12:6863-6889. doi:10.5194/acp-12-68632012

Trenberth KE (1997) Using atmospheric budgets as a constraint on surface fluxes. J Clim 10:2796-2809

Trenberth KE, Stepaniak DP (2003) Covariability of components of poleward atmospheric energy transport on seasonal and interannual timescales. J Clim 16:3691-3705

Uppala SM, Kållberg PW, Simmons AJ, Andrae U, Bechtold VD, Fiorino M, Gibson JK, Haesler J, Hernandez A, Kelly GA, Li X, Onogi K, Saarinen S, Sokka N, Allan RP, Andersson E, Arpe K, Balsamseda MA, Beljaars ACM, Van de Berg L, Bidlot J, Normann N, Caires S, Chevallier F, Dethof A, Dragosavac M, Fisher M, Fuentes M, Hagemann S, Holm E, Hoskins BJ, Isaksen L, Janssen PAEM, Jenne R, McNally AP, Mahfouf JF, Morcrette JJ, Rayner NA, Sauders RW, Simon P, Sterl A, Trenberth KE, Untch A, Vasiljevic D, Voterbo P, Wollen J (2005) The ERA-40 re-analysis. Q J R Meteorol Soc 131:2961-3012

Uttal T, Curry JA, Mcphee MG, Perovich DK, Moritz RE, Maslanik JA, Guest PS, Stern HL, Moore JA, Turenne R, Heiberg A, Serreze MC, Wylie DP, Persson POG, Paulson CA, Halle C, Morison JH, Wheeler PA, Makshtas A, Welch H, Shupe MD, Intrieri JM, Stamnes K, Lindsey RW, Pinkel R, Pegau WS, Stanton TP, Grenfeld TC (2002) Surface heat budget of the Arctic Ocean. Bull Am Meteorol Soc 83:255-276

Valcke S (2006) OASIS3 user guide (prism_2-5). PRISM report series, no 2, 6th edn. [http://www.prism.enes.org/Publications/ Reports/all_editions/index.php£report02]

van Vuuren DP, Edmonds J, Kainuma M, Riahi K, Thomson A, Hibbard K, Hurtt GC, Kram T, Krey V, Lamarque JF, Masui T, Meinshausen M, Nakicenovic N, Smith SJ, Rose SK (2011) The representative concentration pathways: an overview. Clim Change 109:5-31. doi:10.1007/s10584-011-0148-z

Vavrus S, Waliser D, Schweiger A, Francis J (2009) Simulations of 20th and 21st century Arctic cloud amount in the global climate models assessed in the IPCC AR4. Clim Dyn 33:1099-1115

Vavrus S, Holland M, Jahn A, Bailey D, Blazey B (2011) 21stCentury Arctic climate change in CCSM4. J Clim, in press

Wang X, Key J (2005) Arctic surface, cloud, and radiation properties based on the AVHRR polar pathfinder data set. Part I: spatial and temporal characteristics. J Clim 18(14):2558-2574

Wang M, Overland JE (2009) A sea ice free summer Arctic within 30 years? Geophys Res Lett 36(L07502). doi:10.1029/2009 GL037820

Zhang J, Lindsay R, Steele M, Schweiger A (2008) What drove the dramatic retreat of arctic sea ice during summer 2007? Geophys Res Lett 35(L11505). doi:10.1029/2008GL034005 